\title{
Article \\ Climate Change Impacts on Coastal Wave Dynamics at Vougot Beach, France
}

\author{
Pushpa Dissanayake $^{1, * \mathbb{D}}$, Marissa L. Yates ${ }^{2} \mathbb{D}$, Serge Suanez ${ }^{3}$, France Floc'h ${ }^{4} \mathbb{D}$ and Knut Krämer ${ }^{1} \mathbb{D}$ \\ 1 Coastal Geology and Sedimentology, Institute of Geosciences, 24118 Kiel, Germany; \\ knut.kraemer@ifg.uni-kiel.de \\ 2 Saint-Venant Hydraulics Laboratory, University Paris-Est and Cerema, 49-78401 Chatou, France; \\ marissa.yates@cerema.fr \\ 3 Université de Bretagne Occidentale, CNRS, LETG UMR 6554, Institut Universitaire Européen de la Mer, \\ 29280 Plouzané, France; serge.suanez@univ-brest.fr \\ 4 Université de Bretagne Occidentale, CNRS, LGO UMR 6538, Institut Universitaire Européen de la Mer, \\ 29280 Plouzané, France; france.floch@univ-brest.fr \\ * Correspondence: pushpa.dissanayake@ifg.uni-kiel.de
}

Citation: Dissanayake, P.; Yates, M.L.; Suanez, S.; Floc'h, F.; Krämer, K. Climate Change Impacts on Coastal Wave Dynamics at Vougot Beach, France. J. Mar. Sci. Eng. 2021, 9, 1009. https://doi.org/10.3390/jmse9091009

Academic Editor: Achilleas Samaras

Received: 1 September 2021

Accepted: 10 September 2021

Published: 15 September 2021

Publisher's Note: MDPI stays neutral with regard to jurisdictional claims in published maps and institutional affiliations.

Copyright: (c) 2021 by the authors. Licensee MDPI, Basel, Switzerland. This article is an open access article distributed under the terms and conditions of the Creative Commons Attribution (CC BY) license (https:// creativecommons.org/licenses/by/ $4.0 /)$.
Abstract: Wave dynamics contribute significantly to coastal hazards and were thus investigated at Vougot Beach by simulating both historical and projected future waves considering climate change impacts. The historical period included a major storm event. This period was projected to the future using three globally averaged sea level rise (SLR) scenarios for 2100, and combined SLR and wave climate scenarios for A1B, A2, and B1 emissions paths of the IPCC. The B1 wave climate predicts an increase in the occurrence of storm events. The simulated waves in all scenarios showed larger relative changes at the beach than in the nearshore area. The maximum increase of wave energy for the combined SLR and wave scenarios was 95\%, while only 50\% for the SLR-only scenarios. The effective bed shear stress from waves and currents showed different spatial variability than that of the wave height, emphasizing the importance of interactions between nearshore waves and currents. Increases in the effective bed shear stress (combined scenarios: up to 190\%, and SLR-only scenarios: $35 \%$ ) indicate that the changes in waves and currents will likely have significant impacts on the nearshore sediment transport. This work emphasizes that combined SLR and future wave climate scenarios need to be used to evaluate future changes in local hydrodynamics and their impacts. These results provide preliminary insights into potential future wave dynamics at Vougot Beach under different climate change scenarios. Further studies are necessary to generalize the results by investigating the wave dynamics during storm events with different hydrodynamical conditions and to evaluate potential changes in sediment transport and morphological evolution due to climate change.

Keywords: wave impacts; sea level rise; macro-tidal coast; Delft3D; SWAN; numerical modelling

\section{Introduction}

Waves are one of the dominant forcing factors in coastal systems, regulating hydrodynamics and inundation risks and driving sediment transport and morphological changes [1-5]. Waves can cause significant episodic morphological changes during extreme events, and the resultant changes may be partially recoverable or may lead to long-lasting changes of coastal systems [6-11]. Future climate change scenarios are expected to intensify wave impacts with increases in sea levels and increases in the frequency and intensity of extreme events [1,12-16]. Wave impacts may therefore cause significant coastal hazards affecting local morphology, infrastructure, and industries such as tourism.

Coastal systems are important socio-economic and environmental zones. About $10 \%$ of the world's population live in coastal zones [17], which contain many of the world's megacities and important infrastructure [14], while also hosting diverse flora and fauna [18]. 
Ample recreation opportunities in coastal zones attract tourists, generating millions of euros annually for local communities (e.g., around the Wadden Sea [19]). In Europe (http:/ / www.eurosion.org/reports-online/eurosionspecial.pdf, accessed on 15 April 2021), between 500 and 1000 billion euros are invested annually in the $500 \mathrm{~m}$ coastal band, and $16 \%$ of the European population (70 million people) lives in a coastal community. The existence of sustainable coastal systems depends on management policies, which need to be developed based on comprehensive understanding of the system's response to present and future forcing scenarios [14]. Numerous approaches are used to enhance the understanding of coastal systems under different climate change scenarios, supporting efforts to conserve these unique areas [15].

In the past, most studies of future coastal hazards have focused on the impacts of sea level rise (SLR) on coastal erosion (e.g., using the Bruun Rule [20]) or on flooding risks (e.g., "bathtub" approach of passive flooding [21]). In general, SLR is expected to increase the impacts of waves on beaches, since larger waves will reach the original shoreline and propagate farther inland [22]. However, the impacts of SLR on beaches depend strongly on the nearshore and beach characteristics, and it is widely accepted that the hydrodynamic and morphological response depends strongly on the local environment [23]. SLR is not the only physical process impacting coastal hazards, and more recent work highlights the importance of simulating the interactions between changes in water levels and waves, specifically in evaluating extreme water levels during coastal flooding events $[15,24,25]$.

Projections of future hydrodynamic forcing in coastal systems have high uncertainties that must be evaluated using probabilistic approaches [12,26,27]. The IPCC (Intergovernmental Panel of Climate Change) Fifth Assessment Report [12] estimated global mean sea level rise in 2100 for four different emissions scenarios, called Representative Concentration Pathways (RCPs). For each RCP, the median and likely range of global mean sea level rise was calculated based on simulations from 21 process-based models. Projected future wave climates indicate the occurrence of more intense storm events and changes in the average and mean wave conditions in some areas, with high regional variability $[13,24,27]$. Downscaling of global general circulation models (GCMs) may be used to generate nearshore wave conditions, but these approaches are intensive $[15,24]$ and may be difficult to put in place in many coastal environments. Where reliable projections of wave conditions are not yet available, Banno and Kuriyama [26] projected historical wave time series to the future using statistics calculated from different climate change scenarios. In the present study, this method was used to make projections of future wave climates at a local study site, while adopting the global mean and range of SLR estimates from the IPCC [12].

Numerical models are widely used to simulate wave dynamics and the subsequent impacts of water levels and currents in coastal systems at various spatiotemporal scales $[3,28,29]$. For example, the impacts of climate variability on waves and alongshore sediment transport patterns in the Anapa bay-bar coastline in the Black Sea were simulated over the period 1979-2017 using MIKE SW [29]. The results showed that swell waves increased from the SSE direction and decreased from the WSW direction. This caused spatially variable changes in the swell contribution to sediment dynamics, leading to different erosion and sedimentation patterns along the coastline. Using SWASH, Medellín et al. [30] simulated wave runup on the Yucutan coast of Mexico with present and future (2030-2054) forcing scenarios, including the influence of both SLR (global mean change) and changes in the wave climate (using a statistical approach based on the RCP8.5 scenario). The simulation results showed spatial variability in changes in the wave dynamics, with no significant increases in the storm impact regime between the present and future conditions unless SLR was also considered. To estimate accurately the impacts of SLR, the authors concluded that it should be incorporated in the mean sea level prior to performing numerical wave runup simulations, rather than simply adding it to the resulting wave-induced water levels. Furthermore, when studying large-scale wave climate trends, Dodet et al. [31] used Wavewatch3 (WW3) to simulate decadal-scale wave climate variability in the north-east Atlantic Ocean over 57 years (1953-2009). They observed that wave heights decreased from 
high $\left(55^{\circ}\right)$ to low $\left(35^{\circ}\right)$ latitudes, with a significant increase in $\mathrm{Hs}_{90}$ at northern latitudes $\left(55^{\circ}\right)$, reaching up to $1.2 \mathrm{~m}(0.02 \mathrm{~m} /$ year $)$ during the study period.

These studies demonstrate the capacity of numerical models to investigate wave dynamics in different environments and forcing conditions. However, simulations of wave conditions are sensitive to the wind forcing and the parameterization of wave dissipation. In addition, climate change impacts on wave dynamics depend strongly on the geographical location of interest, due to both the regional variability in climate changes (e.g., SLR, wind forcing, and wave conditions) and the particularities of each site (e.g., nearshore bathymetry, tidal regime, and morphological changes). In the long run, coastal-scale and site-specific studies are necessary for developing local-scale management policies. In this study, historical and future wave dynamics were simulated at Vougot Beach, France, at high spatiotemporal scales, using the SWAN model [32] coupled with the Delft3D model [33].

Vougot Beach is a macrotidal environment, located in north Brittany (France). Nearshore hydrodynamic observations (wave heights and water levels) were recorded during several field campaigns [9] and wave heights simulated with the WW3 model are available offshore of the study area with a spatial resolution of up to $600 \mathrm{~m}$ [34]. Previously, the in situ measurements were compared with the offshore simulated waves from WW3 to investigate the wave hydrodynamics at this coast [9]. In the current study, a local-scale model propagating waves to the nearshore zone and beach, including the highly variable nearshore bathymetry, was developed. With a validated model, potential future changes in wave dynamics can be investigated at high spatiotemporal resolution by forcing the model with the projected waves and water levels based on climate change scenarios. Existing studies along this coast have not addressed these aspects, which are of utmost importance for policy makers to identify the suitable management strategies to mitigate coastal hazards. In addition, few studies of the combined impacts of future SLR and wave climate changes exist on macrotidal beaches [35].

The main objective of this study was to compare historical and future local wave dynamics at Vougot Beach with high spatiotemporal resolution and to evaluate potential changes caused by climate change impacts. The novelty of the approach is in simulating wave dynamics for an observed wave time series and the future projection of the same wave time series by considering the effects of both SLR and the impacts of future emissions scenarios on the local wave climate. It was hypothesized that future climate change scenarios will increase wave dynamics at this coast, thus increasing the vulnerability to coastal hazards and the risks of erosion and flooding.

To achieve this, Section 2 describes the study area and field data, and Section 3 details the applied approach. The results are presented in Section 4, with a discussion of the limitations of the current study and suggestions for future work in Section 5. Finally, the conclusions of the study are presented in Section 6, including the general applicability of this work.

\section{Study Site}

\subsection{Location}

Vougot Beach is located in the community of Guissény, France (Figure 1a,b). This coastal zone is one of the elements composing a vast landscape unit identified as the "coastal bench of the northern coast of Plateau of Leon" [36], creating complex local bathymetry and hydrodynamics at the study site (Figure 1d). The coastal bench is a string of low coastal regions (altitudes $<15 \mathrm{~m}$, all elevation and depth values are referred to the French datum: NGF (nivellement général de la France). A submarine scarp between $10 \mathrm{~m}$ and 40 to $60 \mathrm{~m}$ depth delimits the outer edge of a large platform with reefs and islets ( 3 to $6 \mathrm{~km}$ wide), on which Holocene sandy accumulations form the current beach/dune systems, such as Vougot Beach [37-39]. These reefs and inlets determine the complex morphology of the foreshore and offshore zones of Vougot Beach, causing complex nearshore hydrodynamics (i.e., wave and currents) [10]. In recent decades, the dune at the eastern part of the beach (Figure 1d, corresponding to the study site here) has experienced chronic retreat reaching 
$0.7 \mathrm{~m} /$ year [40]. The study area (Figure 1d) is relatively protected from waves originating in the west to the northwest by the platform scattered with islets and reefs that emerge at low tide, such as Karreg Hir, Golhédoc or Enez Du (Figure 1c).

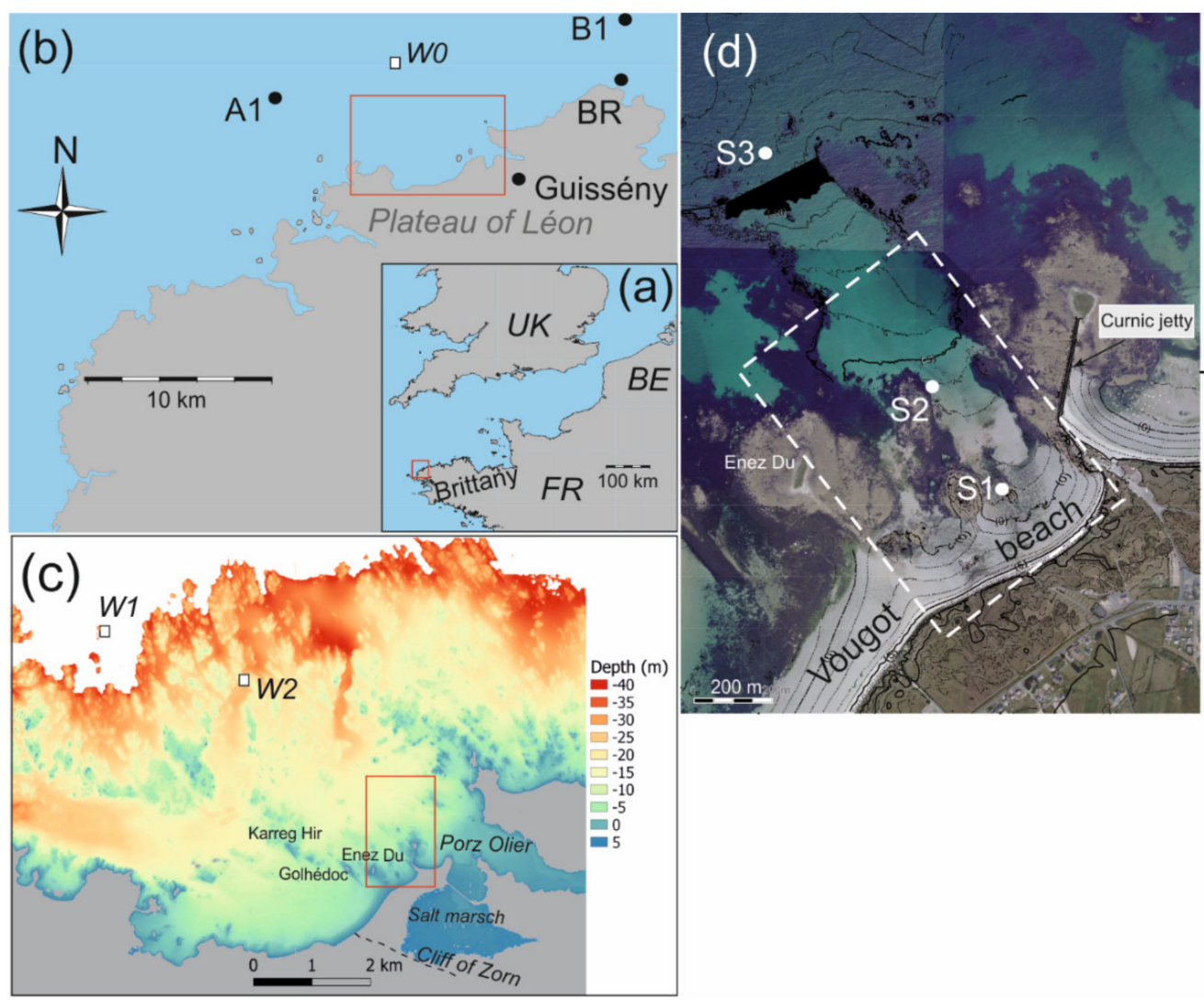

Figure 1. Location of Vougot beach on the north coast of Finistere in Brittany, France (a) in the municipality of Guisseny (b), showing the Brignogan wind measuring station from Météo France (BR: $48.68^{\circ} \mathrm{N} 4.33^{\circ} \mathrm{W}$ ), and the offshore corner points $\left(\mathrm{A}_{\mathrm{G} 1}\right.$ and $\mathrm{B}_{\mathrm{G} 1}$ ) of the coarse-grid model domain (G1 in Figure 4). Topo-bathymertry of the northern coast of Finistère (c), including the study site (digital elevation model Litto3D-Finistère 2014, produced by IGN and SHOM, https: / / diffusion.shom.fr/pro/risques/litto3dr-finistere-2014.html, accessed on 22 January 2015) W1 $\left(48.67^{\circ} \mathrm{N} 4.53^{\circ} \mathrm{W}, 44 \mathrm{~m}\right.$ depth) and $\mathrm{W} 2\left(48.65^{\circ} \mathrm{N} 4.39^{\circ} \mathrm{W}, 23 \mathrm{~m}\right.$ depth) are the locations of waves. Satellite image of Vougot Beach (d) indicating the study area (dashed white rectangle) and the location of the pressure sensors (S1, S2 and S3). Red rectangles show the spatial extent of each subsequent inset.

The macrotidal range, reaching $8.4 \mathrm{~m}$ for astronomical tides, is responsible for the large intertidal beach surface, which can expose more than $400 \mathrm{~m}$ in the cross-shore at low tide. The most energetic waves come from the west to north sector with an average significant wave height $(\mathrm{Hs})$ between 1 and $1.5 \mathrm{~m}$, and an average peak period $(\mathrm{Tp}$ ) between 9 and $10 \mathrm{~s}$. The largest storm wave heights and periods (respectively $\geq 10 \mathrm{~m}$ and $8 \mathrm{~s}$ ) occur between December and February [10]. During spring, the waves are less energetic (35\% of waves with $H s=2-4 \mathrm{~m}$ and $\mathrm{Tp}=8-12 \mathrm{~s}$ ), before an increase in fall with $H$ s reaching up to $10 \mathrm{~m}$ approximately $20 \%$ of time. Wind data recorded at the Brignogan Météo France station $(\mathrm{BR}$, Figure $1 \mathrm{~b})$ show that the most frequent annual winds are from the south to west sector, with a moderate north-east component. The strongest wind velocities $(>8 \mathrm{~m} / \mathrm{s}$ more than $30 \%$ of the time) blowing from north-west to south-west occur generally during winter (December to February, generating mainly west-northwest waves (96\%) [10]. During the summer (June to August), winds are much weaker (generally $\leq 4.5 \mathrm{~m} / \mathrm{s}$ ), before increasing again in the fall. 


\subsection{Data}

In this study, observations of water levels, wave characteristics, wind data, and bathymetry were retrieved from existing databases and field studies covering a period from 7 January to 18 February 2013, during which major storms impacted Vougot Beach [9].

Three pressure sensors S1, S2, and S3 (OSSI-010-003C, Ocean Sensor Systems Inc. ${ }^{\circledR}$, accuracy $\pm 1.5 \mathrm{~cm}$ ) were deployed to measure water levels and wave characteristics in the nearshore region of Vougot Beach (Figure 1d). Each sensor was set to a recording frequency of $5 \mathrm{~Hz}$ to measure water level variations with high temporal resolution. S1 and S2 were deployed at $0.7 \mathrm{~m}$ and $2.5 \mathrm{~m}$ depth, representing the mid and lower zones of the intertidal beach, respectively. Therefore, S1 and S2 emerged out of the water twice a day during low tide. S3 measured water levels farther offshore in $12.0 \mathrm{~m}$ depth, and thus remained permanently submerged.

The OSSI pressure data were corrected for the (1) atmospheric mean sea level pressure recorded at the Brignogan Météo France station (BR in Figure 1b) and (2) non-hydrostatic pressure following linear wave theory [41,42]. The mean surface elevation was extracted using a $10 \mathrm{~min}$ moving average. The wave spectrum and wave-averaged parameters were calculated from the Fourier transform (1024 data points over the incident gravity wave band, between 0.04-0.4 Hz). A Hamming window was applied to the signal (with zero values at the end) and $15 \mathrm{~min}$ [43] averages were calculated for several contiguous spectra with $50 \%$ overlap to avoid leakage issues related to a signal that was not perfectly periodic. The mean spectral wave parameters, i.e., significant wave height $(H s)$ and the equivalent spectral mean period, were computed in each frequency band [44].

The predicted astronomical tides at $\mathrm{A}_{\mathrm{G} 1}$ and $\mathrm{B}_{\mathrm{G} 1}$ (see Figure $1 \mathrm{~b}$ ) were obtained from the tidal database of European Shelf 2008 (ES2008) using the online tool Delft Dashboard, (https:/ / publicwiki.deltares.nl/display/DDB/Delft+Dashboard, accessed on 15 December 2020). During the analysis period, the average phase difference between locations $A_{G 1}$ and $\mathrm{B}_{\mathrm{G} 1}$ was about $10 \mathrm{~min}$, and the spring and neap tidal ranges were approximately $7.5 \mathrm{~m}$ and 2.4, respectively (Figure 2a). The maximum tidal anomaly (TA: total water level-astronomical tide) reached up to $1.1 \mathrm{~m}$ during the storm event that occurred around 6 February 2013, caused primarily by storm surge at this water depth.

Hindcast wave time series were obtained from the HOMERE wave database, generated with the spectral wave model WW3 (see Boudière et al. [34] for more details). Wave characteristics were extracted at locations $\mathrm{W} 1\left(48.67^{\circ} \mathrm{N} 4.53^{\circ} \mathrm{W}\right)$ and $\mathrm{W} 2\left(48.65^{\circ} \mathrm{N}\right.$ $4.39^{\circ} \mathrm{W}$ ), in $44 \mathrm{~m}$ and $23 \mathrm{~m}$ depth, respectively (Figure 1c). During the six-week analysis period from 7 January-18 February 2013, more than 4 storm events showed Hs exceeding $4 \mathrm{~m}$ at the deeper water location (W1, Figure $2 \mathrm{~b}$ ), including one event with $H$ s exceeding $6 \mathrm{~m}$, with large waves arriving primarily from the northwest.

Wind measurements used in this study were provided by Météo France at the Brignogan station (BR, Figure 1b). Strong winds during the study period primarily originated from the northwest (Figure 2c), and the wind velocities often exceeded $8 \mathrm{~m} / \mathrm{s}$, occasionally reaching 15 to $20 \mathrm{~m} / \mathrm{s}$ during the most extreme events (i.e., 6 February 2013).

The bathymetry data were collected from two sources. The first set was a highresolution $(1 \mathrm{~m} \times 1 \mathrm{~m})$ bathymetry from the digital elevation model Litto3D ${ }^{\circledR}$ (https:/ / diffusion.shom.fr/pro/risques/litto3dr-finistere-2014.html, accessed on 22 January 2015), produced by the IGN and SHOM using measurements from 2013. These data spanned about $6 \mathrm{~km}$ in the cross-shore direction, extending to about $40 \mathrm{~m}$ depth (Figure 1c). The second dataset was obtained from the GEBCO 08 (General Bathymetric Chart of the Oceans) bathymetry database through Delft Dashboard. These data had a very coarse spatial resolution $(\sim 600 \mathrm{~m})$ around the study area, and were therefore only used for water depths greater than $35 \mathrm{~m}$ to span the region between the Litto3D bathymetry and the offshore limit of the model domain. 


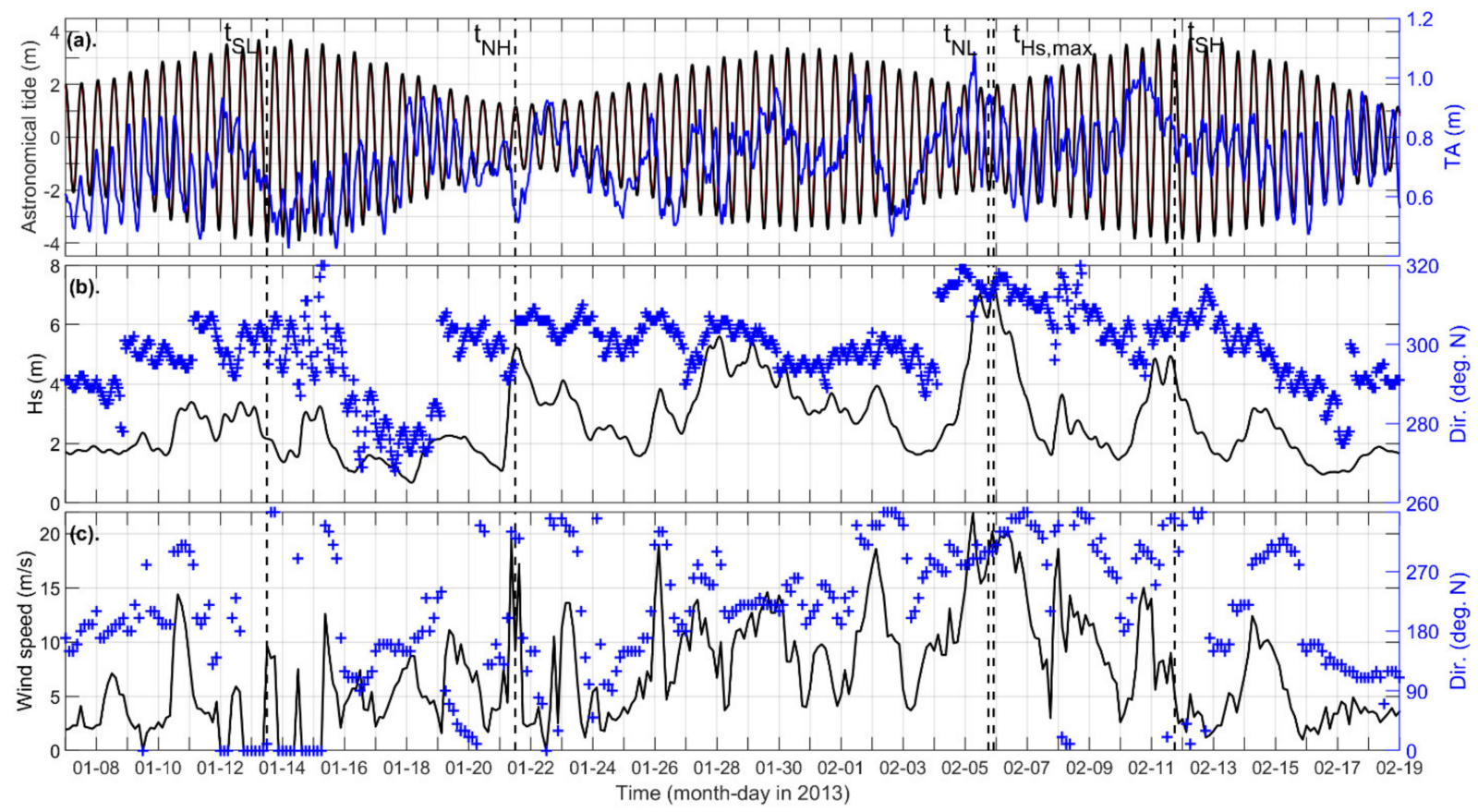

Figure 2. Data used for the numerical simulations. (a) Predicted astronomical tide at $\mathrm{A}_{\mathrm{G} 1}$ (red line) and $\mathrm{B}_{\mathrm{G} 1}$ (black line). Note that the red line is not visible because there was only a 10 min phase shift between the time series at $A_{G 1}$ and $B_{G 1}$. The blue line is the derived tidal anomaly (TA) at S3 (Figure 1d). (b) Significant wave height (black line) and direction (blue crosses) at W1 (Figure 1b) from the WW3 model. (c) Measured wind speed (black line) and direction (blue crosses) at BR (Figure 1b).

\section{Approach}

To study the impacts of climate change on the nearshore hydrodynamics at Vougot Beach, a series of numerical simulations were carried out using past observations and hindcast simulations of water levels, waves, and winds. The same time series was projected into the future using SLR projections to adapt the water level and a statistical approach to project the wave time series to the future.

\subsection{Future Scenarios}

\subsubsection{Sea Level Rise}

Existing global and regional sea level rise scenarios were assessed to select the water level scenarios to be used in this study. The 5th Assessment Report of IPCC estimated the median global mean sea level rise to be $0.74 \mathrm{~m}$ (ranging from $0.53-0.98 \mathrm{~m}$ ) in 2100 following the RCP8.5 [12]. The RCP8.5 was selected since it is the most pessimistic concentration pathway scenario ('business as usual'). The median and range of expected values in 2100 were calculated from the results of the process-based projections from 21 Coupled Model Intercomparison Project phase 5 (CMIP5) Atmosphere-Ocean General Circulation Models (AOGCMs). At the regional scale, the Integrated Climate Data Center (ICDC) provides predictions of local sea level rise rates, and offshore of the study site, the closest projection location estimates approximately $0.67 \mathrm{~m}$ of sea level rise in 2100 (also following the RCP8.5). This value falls within the range of global SLR estimates, and thus, the three values of global SLR estimates provided in the IPCC report were retained for the analyses here: SLRmin $=0.53 \mathrm{~m}, \mathrm{SLR}$ avg $=0.74 \mathrm{~m}$, and SLRmax $=0.98 \mathrm{~m}$. The recent 6 th Assessment Report updated global mean SLR estimates by 2100 (e.g., intermediate, SSP2-4.5: 0.44-0.77 $\mathrm{m}$ and very high, SSP5-8.5: 0.63-1.01 $\mathrm{m}$ emissions scenarios), and the values retained in this study are consistent with the updated predictions. 


\subsubsection{Wave Climate}

To estimate the impacts of climate change on the wave field, a statistical approach was adopted following Banno and Kuriyama [26]. They suggested that projected changes in the wave field can be estimated by adjusting past wave time series with the predicted changes in the wave statistics (i.e., mean, standard deviation, log-normal distribution). Their approach was applied to project a six-week time period during the 2012-2013 winter to the future by adjusting the significant wave height $(H s)$, peak wave period $(T p)$, wave direction $(\theta)$, and directional spreading $\left(\sigma_{\theta}\right)$. Given the limitations of the time period and spatial coverage of existing wave databases, this analysis was carried out in two steps using two different wave databases to estimate projected changes in offshore wave conditions and the appropriate transfer function to transform offshore waves to nearshore waves (at W1: $48.67^{\circ} \mathrm{N} 4.53^{\circ} \mathrm{W}$, Figure $1 \mathrm{c}$ ).

The projected changes in the offshore wave conditions (at W0: $48.69^{\circ} \mathrm{N} 4.52^{\circ} \mathrm{W}$, Figure $1 \mathrm{~b}$ ) were estimated using the database created by Laugel [45], who simulated wave conditions in the North Atlantic using a dynamical downscaling approach. A hindcast period from 1961-2000 and a forecast period from 2061-2100 were simulated using the spectral wave model TOMAWAC [46], which was run with the same model configuration for both time periods (see Laugel [45] for more details). Concerning the wind forcing conditions, two different scenarios were considered: for the hindcast period, the results of ARPEGE-CLIMAT global climate model simulations [47] and for the forecast period, projected scenarios following the emissions scenarios A1B, A2, and B1 [48]. In this study, two relatively pessimistic emissions scenarios were selected to generate the wave projections to investigate the scenarios causing the largest potential changes.

The difference between the hindcast and forecast periods was estimated by calculating: the log-normal distribution of $H s$ during the two time periods (considering changes in the mean and extreme values), and the mean and standard deviation of $T_{p}, \theta$, and $\sigma_{\theta}$. The hindcast wave time series were transformed by adjusting each value of $H s, T_{p}, \theta$, and $\sigma_{\theta}$ to correspond to forecast values using the updated distributions, producing a 6-week long future time series at the offshore point W0 (Figure 1b).

In the second step, linear transformation functions (for $H s, T_{p}, \theta$, and $\sigma_{\theta}$ ) were calculated using the past observations at W0 and W1 to estimate the transformed wave time series at W1 (Figures $1 \mathrm{c}$ and 3 ). Using this approach, Hs exceeded $6 \mathrm{~m}$ during one event in the hindcast time series, while it exceeded this threshold during three events in the B1 forecast time series. A1B and B1 had larger wave heights than A2, with B1 showing the largest wave heights overall. Dominant wave directions were fairly similar in all forecasts compared with the past waves (Figure 3b-e).

\subsection{Numerical Modelling}

The Delft3D model was used to simulate the local hydrodynamics at Vougot Beach with high spatiotemporal resolution. After calibrating the model with past observations, changes in the local hydrodynamics were evaluated for different scenarios of the projected SLR and wave climate changes.

\subsubsection{Delft3D}

Delft3D is an open-source model that has shown skill in simulating wave dynamics for a wide range of case studies [3,11,49]. Delft3D is a three-dimensional model based on a finite difference approach $[33,50,51]$. In this analysis, a depth-averaged approach (2DH) was used. The wave dynamics were simulated by online wave coupling with the wave model, SWAN [32], which allows simulating wave-current interactions at a specified time interval. A $1 \mathrm{~h}$ interval was used to capture the tidal variation, even though the temporal resolution of the wind and wave data was $3 \mathrm{~h}$. At a complex study site such as Vougot Beach, with high bathymetric variability and a macrotidal regime, it is important to include wave-current interactions to simulate accurately wave dynamics. 

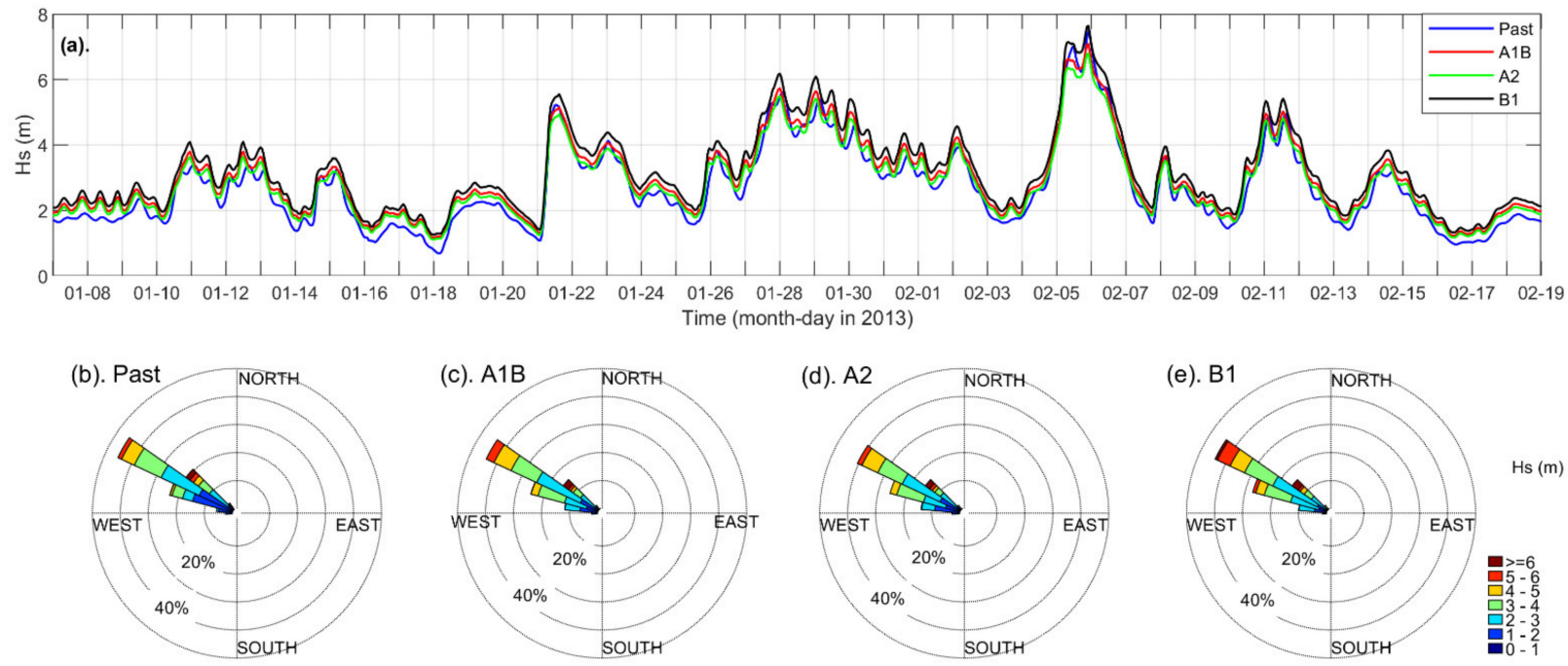

Figure 3. Comparison of (a) wave height and wave roses during the (b) historical period from 7 January-18 February 2013, and (c) A1B, (d) A2, and (e) B1 future wave projections at W1.

\subsubsection{Model Domains and Boundary Forcing}

A nested modelling approach was used to initiate the model offshore in deep-water conditions (G1 domain) and to refine progressively the model grids to simulate high spatial resolution wave dynamics in the nearshore region (G3 domain in Figure 4a and Table 1). The large-scale, coarse-grid G1 domain was used to simulate only the astronomical tide to provide the appropriate boundary conditions for the G2 domain, including the tidal phase difference between $\mathrm{A}_{\mathrm{G} 2}$ and $\mathrm{B}_{\mathrm{G} 2}$ (Figure $4 \mathrm{~b}$ ). Wave-current interactions were then simulated in the G2 and G3 domains with progressively finer grids.

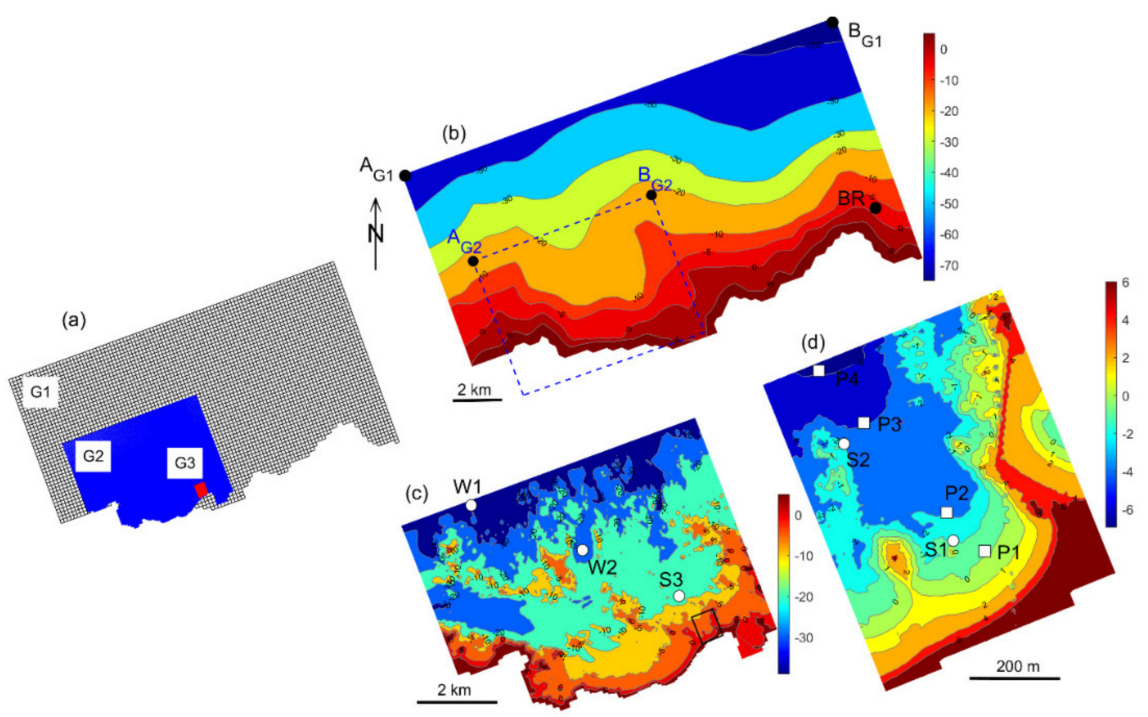

Figure 4. Model setup: (a) nested model grids, G1, G2, and G3; (b) bathymetry of the large-scale $\mathrm{G} 1$ grid, astronomical tides were obtained at $\mathrm{A}_{\mathrm{G} 1}$ and $\mathrm{B}_{\mathrm{G} 1}$ from the ES2008 tidal database, $\mathrm{BR}$ is the Brignogan wind station, the dashed blue line indicates the extent of the $\mathrm{G} 2$ grid, and $\mathrm{A}_{\mathrm{G} 2}$ and $\mathrm{B}_{\mathrm{G} 2}$ are the locations where the simulated water levels were extracted for G2. (c) Bathymetry of the G2 grid, where W1 and W2 indicate the wave data points from WW3 (HOMERE database), S3 is the offshore pressure sensor, and the black square indicates the extent of the G3 grid. (d) Bathymetry of the study area (G3), where S1 and S2 are nearshore pressure sensors and P1 to P4 are the selected locations to analyze the wave dynamics. 
Table 1. Characteristics of the G1, G2, and G3 model domains (Figure 4).

\begin{tabular}{cccc}
\hline Model Domain & $\begin{array}{c}\text { Spatial Extent } \\
\text { (Alongshore } \times \text { Cross Shore in km) }\end{array}$ & Grid Type & $\begin{array}{c}\text { Grid Resolution } \\
\text { (Alongshore } \times \text { Cross Shore in m) }\end{array}$ \\
\hline G1 & $20 \times 10$ & rectilinear & $200 \times 200$ \\
\hline G2 & $8 \times 6$ & curvilinear & $40-50 \times 20-60$ \\
\hline G3 & $0.5 \times 0.7$ & curvilinear & $9 \times 4-5$ \\
\hline
\end{tabular}

The model bathymetries were created using the two sources of data. The G1 bathymetry $(200 \mathrm{~m} \times 200 \mathrm{~m}$, the same scale as the model grid) was based on the GEBCO 08 (https: //publicwiki.deltares.nl/display/DDB/Delft+Dashboard, accessed on 15 December 2020) dataset and did not represent the strong bathymetric variations in the nearshore region (Figure $4 \mathrm{~b}$ ). The G2 and G3 bathymetries were constructed by interpolating the high-resolution $(1 \mathrm{~m} \times 1 \mathrm{~m})$ digital elevation model Litto3D ${ }^{\circledR}$ (https:/ / diffusion.shom.fr/pro/risques/litto3 dr-finistere-2014.html, accessed on 22 January 2015) (Figure 4c,d) onto the 2 models' grids to capture the finer details of the bathymetric variations. However, the offshore area of G2 was not entirely covered by this dataset, and the data gaps were filled by triangular interpolation using neighboring available depth values (Figure 4c). The highest resolution grid, G3, represented the finer details of the bathymetry well, with a resolution of less than $10 \mathrm{~m}$ in the cross-shore and alongshore directions representing the jetty of Curnic and the reef at the eastern and western ends of the domain, respectively (see Figures $1 \mathrm{~d}$ and $4 \mathrm{~d}$ ).

The $\mathrm{G} 1$ domain was forced with the astronomical tide level defined at $\mathrm{A}_{\mathrm{G} 1}$ and $\mathrm{B}_{\mathrm{G} 1}$ from the ES2008 (https:/ / publicwiki.deltares.nl/display/DDB/Delft+Dashboard, accessed on 15 December 2020) tidal database (Figure 4b). In Delft3D, the water level was specified at the offshore boundary, while the water level gradients were specified for the lateral boundaries. This combination of boundary conditions generates tidal currents perpendicular to the lateral boundaries, following the direction of tidal propagation (see details in Roelvink and Walstra [52]). The nested grid G2 was forced with both the total water levels (using the same approach as for G1) and the waves. The total water levels at the offshore corner points $\mathrm{A}_{\mathrm{G} 2}$ and $\mathrm{B}_{\mathrm{G} 2}$ were calculated as the sum of the simulated astronomical tide from G1 and TA at the pressure sensor at S3 (Figure 2a). For the wave boundary of G2, spatially uniform wave conditions were applied along the offshore boundary based on the wave characteristics estimated at W1. A JONSWAP spectrum (Joint North Sea Wave Project [53-55]) was used to specify the wave conditions at the boundary. G3 was nested in the G2 wave model, and thus the G3 boundary conditions were input directly from the G2 wave and water level simulations. The high-resolution G3 domain was, therefore, simulated including the effects of wave-current interactions with the tidal variations.

\subsubsection{Model Simulations}

The local hydrodynamics at Vougot Beach were investigated with observations from the 2012-2013 winter and with 7 different scenarios of potential changes in sea level and wave climate (Table 2).

The future SLR and wave climate scenarios were described in Section 3.1. The three SLR scenarios were simulated using the historical wave time series to investigate the relative impacts of only SLR on the wave dynamics along this coast. However, climate change will likely impact sea levels and wave climates simultaneously, so combined scenarios (SLR and waves) were developed considering four different combinations of SLR (min and max) and wave climate (A1B and B1) scenarios. Each simulation thus spanned the six-week analysis period from 7 January-18 February 2013, or the equivalent six-week period projected into the future. 
Table 2. Summary of the water level and wave conditions used in each model simulation: (1) reference time period from 7 January-18 February 2013 and projected simulations considering $(2,3,4)$ SLR-only and $(5,6,7,8)$ four different combinations of SLR and projected wave conditions.

\begin{tabular}{|c|c|c|c|}
\hline Simulation & Scenario & & Description \\
\hline 1 & Reference & & $\begin{array}{l}\text { Water levels }=\text { astronomical tides at } \mathrm{A}_{\mathrm{G} 2} \text { and } \mathrm{B}_{\mathrm{G} 2}+\mathrm{TA} \text { at } \mathrm{S} 3 \\
\text { (Figure } 1 \text { ) } \\
\text { Wave characteristics at W1 from WW3 (Figure 1) } \\
\text { Wind data at BR, Brignogan (Figure 1) }\end{array}$ \\
\hline 2 & \multirow{7}{*}{$\begin{array}{l}\text { Combined sea level rise and } \\
\text { future wave climate }\end{array}$} & $\mathrm{SLR}_{\min }$ & $\begin{array}{c}\text { Only water level increased by } 0.53 \mathrm{~m} \text { : minimum of global } \\
\text { range by IPCC [16] }\end{array}$ \\
\hline 3 & & SLR $_{\text {avg }}$ & $\begin{array}{c}\text { Only water level increased by } 0.74 \mathrm{~m} \text { : average of global } \\
\text { range by IPCC [16] }\end{array}$ \\
\hline 4 & & $\mathrm{SLR}_{\max }$ & $\begin{array}{l}\text { Only water level increased by } 0.98 \mathrm{~m} \text { : maximum of global } \\
\text { range by IPCC [16] }\end{array}$ \\
\hline 5 & & $\mathrm{SLR}_{\min }+\mathrm{A} 1 \mathrm{~B}$ & $\begin{array}{l}\text { Water level SLR } \text { min }_{\text {min }} \\
\text { Waves based on A1B of IPCC [16] }\end{array}$ \\
\hline 6 & & $\mathrm{SLR}_{\max }+\mathrm{A} 1 \mathrm{~B}$ & $\begin{array}{c}\text { Water level SLR } \text { max }_{\text {max }} \\
\text { Waves based on A1B of IPCC [16] }\end{array}$ \\
\hline 7 & & $\mathrm{SLR}_{\min }+\mathrm{B} 1$ & $\begin{array}{l}\text { Water level SLR } \text { min }_{\text {m }} \\
\text { Waves based on B1 of IPCC [16] }\end{array}$ \\
\hline 8 & & $\mathrm{SLR}_{\max }+\mathrm{B} 1$ & $\begin{array}{c}\text { Water level SLR } R_{\max } \\
\text { Waves based on B1 of IPCC [16] }\end{array}$ \\
\hline
\end{tabular}

\subsection{Analysis}

After simulating the reference period and the seven future scenarios, changes in the nearshore hydrodynamics (water levels, waves, and currents) were investigated at Vougot Beach. The results of the future simulations were compared to those of the reference simulation using the following analytical parameters: significant wave height as defined from the wave spectrum), wave spectral density, and effective bed shear stress.

(a) Wave spectral density

The wave spectral density $(S D)$ represents the distribution of wave energy as a function of frequency and its shape depends on the processes of wave growth and decay, as well as interactions between different frequency bands. In this analysis, wave spectral density was estimated based on the JONSWAP spectrum $[53,54]$.

$$
S D(f)=\frac{\alpha g^{2}}{(2 \pi)^{4} f^{5}} \exp \left[\frac{-5}{4}\left(\frac{f}{f_{p}}\right)^{-4}\right] \gamma^{r}
$$

where, $r=\exp \left[\frac{-\left(f-f_{p}\right)^{2}}{2 \sigma^{2} f_{p}^{2}}\right], \sigma=\left\{\begin{array}{l}0.07, f<f_{p} \\ 0.09, f \geq f_{p}\end{array}, \alpha\right.$ : Phillips constant $(-), g$ : acceleration of gravity $\left(\mathrm{m}^{2} / \mathrm{s}\right), f$ : wave frequency $(\mathrm{Hz}), \gamma$ : peak enhancement factor (3.3), $\sigma$ : spectral width parameter (-), and $t$ : time (s).

To evaluate changes in the wave spectral density, the average wave spectral density $S D_{\text {avg }}\left(\mathrm{J} / \mathrm{m}^{2} / \mathrm{Hz}\right)$ was calculated for each analysis period of length $T$ (s) as:

$$
S D_{\text {avg }}=\frac{1}{T} \int_{0}^{T} S D(f) d t
$$


The relative change of the averaged wave spectral density with respect to the reference scenario $S D_{\text {rel, } i}$ was calculated for each future scenario, $i$ as:

$$
S D_{\text {rel }, i}=\left(\frac{S D_{a v g, i}-S D_{a v g, p a s t}}{S D_{a v g, p a s t}}\right) \times 100 \%
$$

\section{(b) Effective bed shear stress}

The effective bed shear stress $\left(\tau_{\mathrm{b}}\right)$ is an important parameter in an investigation the effects of wave dynamics in areas where both currents and waves strongly impact the hydrodynamics. This provides overall shear stress on the sea floor from both waves and currents, and their interactions, and determines local sediment transport, which will be investigated in the next phase of this study. The depth-averaged effective bed shear stress was calculated following the approach of Soulsby [56], using one standard function that can be adapted for different wave-current boundary layer models using different fitting coefficients (https: / / content.oss.deltares.nl/delft3d/manuals/Delft3D-FLOW_User_Manual.pdf, accessed on 19 May 2021). Of the several models available, the Fredsøe [57], boundary layer model was used in this study following the common approach [58]:

$$
\begin{gathered}
\overrightarrow{\tau_{b}}=\frac{\left|\overrightarrow{\tau_{m}}\right|}{|u|}\left(\vec{u}+\overrightarrow{u_{s}}\right) \\
\left|\overrightarrow{\tau_{m}}\right|=Y\left(\left|\overrightarrow{\tau_{c}}\right|+\left|\overrightarrow{\tau_{w}}\right|\right) \\
\tau_{w}=\frac{1}{2} \rho f_{w} u_{w}^{2} \\
\tau_{c}=\rho C_{D} u^{2}
\end{gathered}
$$

where $\tau_{m}$ : bed shear stress of combined waves and currents $\left(\mathrm{N} / \mathrm{m}^{2}\right), u$ : depth-averaged velocity $(\mathrm{m} / \mathrm{s}), u_{s}$ : depth-averaged Stokes drift, $Y:$ a fitting function for the wave-current boundary layer [59], $\tau_{c}$ : bed shear stress from currents alone $\left(\mathrm{N} / \mathrm{m}^{2}\right), \tau_{w}$ : bed shear stress from waves alone $\left(\mathrm{N} / \mathrm{m}^{2}\right), \rho$ : water density $\left(\mathrm{kg} / \mathrm{m}^{3}\right), f_{w}$ : friction factor $(-), u_{w}$ : wave orbital velocity $(\mathrm{m} / \mathrm{s})$, and $C_{D}$ : drag coefficient (-).

The average effective bed shear stress over the analysis period $\left(\tau_{b, a v g}\right)$ was calculated as,

$$
\tau_{b, a v g}=\frac{1}{T} \int_{0}^{T} \tau_{b} d t
$$

\section{(c) Statistical parameters}

The model's skill in predicting water levels and wave heights was compared to the observations during the reference period, and then changes in the wave dynamics were estimated by comparing the future scenarios to the reference simulation using four statistical parameters (Equations (9)-(12)).

The coefficient of determination $\left(R^{2}\right)$ was calculated to quantify the fraction of variance in each simulation corresponding to either the measurements or the reference simulation. This is defined as the squared value of the coefficient of correlation [59]:

$$
R^{2}=\left[\frac{\sum_{j=1}^{n}\left(x_{j}-\bar{x}\right)\left(y_{j}-\bar{y}\right)}{\sqrt{\left(x_{j}-\bar{x}\right)\left(y_{j}-\bar{y}\right)}}\right]^{2}
$$

where, $x$ values represent the parameter time series (e.g., Hs) from either the measured data or the reference simulation and $y$ values represent the simulated hindcast or forecast 
values, $\bar{x}$ and $\bar{y}$ indicate the mean values, and $n$ is the number of time steps during the analysis period.

The root mean square difference (RMSD) quantifies the standard deviation of the differences between the simulations and either the measurements or the reference simulation:

$$
R M S D=\sqrt{\frac{1}{n} \sum_{j=1}^{n}\left(x_{j}-y_{j}\right)^{2}}
$$

Smaller RMSDs imply better agreement between the observations and the model simulations (thus referred to as the RMSE: root mean square error), or smaller changes in future scenarios compared with the reference scenario.

The relative standard deviation $\left(\sigma_{r e l}\right)$ estimates the deviation between the reference and the future scenarios with respect to the averaged value $(\bar{\mu})$ of the normalised difference $\left(\mu_{j}\right)$.

$$
\begin{gathered}
\sigma_{r e l}=\sqrt{\frac{1}{n} \sum_{j=1}^{n}\left(\mu_{j}-\bar{\mu}\right)^{2}} \\
\bar{\mu}=\frac{1}{n} \sum_{j=1}^{n} \mu_{j}
\end{gathered}
$$

where, $\mu_{j}=\frac{\left(y_{j}-x_{j}\right)}{x_{j}}$.

These statistics can be used to compare variations in wave dynamics (e.g., $H s, \tau_{b}$ ) among the scenarios and at different locations at Vougot Beach.

\section{Results}

\subsection{Model Validation}

The model's performance was validated by comparing the simulated water levels and wave heights with the measurements during the study period. Simulated water levels were compared with the water levels derived from the pressure sensor measurements at S1, S2, and S3 (Figure 5a-c). The water level variations varied significantly between each sensor as a function of the water depth.

To analyze the simulated hydrodynamics during characteristic periods of the tidal cycle at Vougot Beach, four dates throughout the analysis period were selected, representing spring-low $\left(t_{\mathrm{SL}}\right)$, neap-high $\left(\mathrm{t}_{\mathrm{NH}}\right)$, neap-low $\left(\mathrm{t}_{\mathrm{NL}}\right)$, and spring-high $\left(\mathrm{t}_{\mathrm{SH}}\right)$ tidal conditions (columns in Figure 5a-c). The date of the peak storm wave height observed during this time period $\left(\mathrm{t}_{\mathrm{Hs}, \max }\right)$ was also selected for comparison. Around $\mathrm{t}_{\mathrm{SL}}$, the measured and simulated water levels agreed qualitatively well, except at S3, where the minima at spring-low water were slightly higher in the model than in the measurements (i.e., maximum difference $\sim 0.3 \mathrm{~m}$ ). Around $\mathrm{t}_{\mathrm{NH}}$, small differences in the measured and simulated water levels were observed at $\mathrm{S} 1$ during ebb tide. The largest differences in water levels at all locations were found around $\mathrm{t}_{\mathrm{NL}}(\mathrm{S} 1 \sim 0.6 \mathrm{~m}, \mathrm{~S} 2 \sim 0.5 \mathrm{~m}$ and S3 0.4 m) during the storm with the large wave heights. These differences may have been caused by modelling errors or by increases in errors in the sensor measurements in the surf and swash zones. The simulated water levels agreed better with the measurements during the flood phase of the tide because of the phase shift between the simulated and measured water level peak at high tide. Both of these phenomena may have an important role during storm events, particularly at $\mathrm{S} 1$. Around $\mathrm{t}_{\mathrm{SH}}$, the water level variations were similar to those around $\mathrm{t}_{\mathrm{SL}}$, with a slight overestimation of the maxima at S1 and the minima at S3.

The simulated water levels agreed well with the measurements with $R^{2}>0.97$ and $R M S E<0.37 \mathrm{~m}$ at $\mathrm{S} 1, \mathrm{~S} 2$, and S3 (Figure $5 \mathrm{~d}-\mathrm{f}$ ). The model was able to reproduce well the amplitude and phase of the measured water levels, with better agreement in deeper water (S3) than in shallow water (S1). 

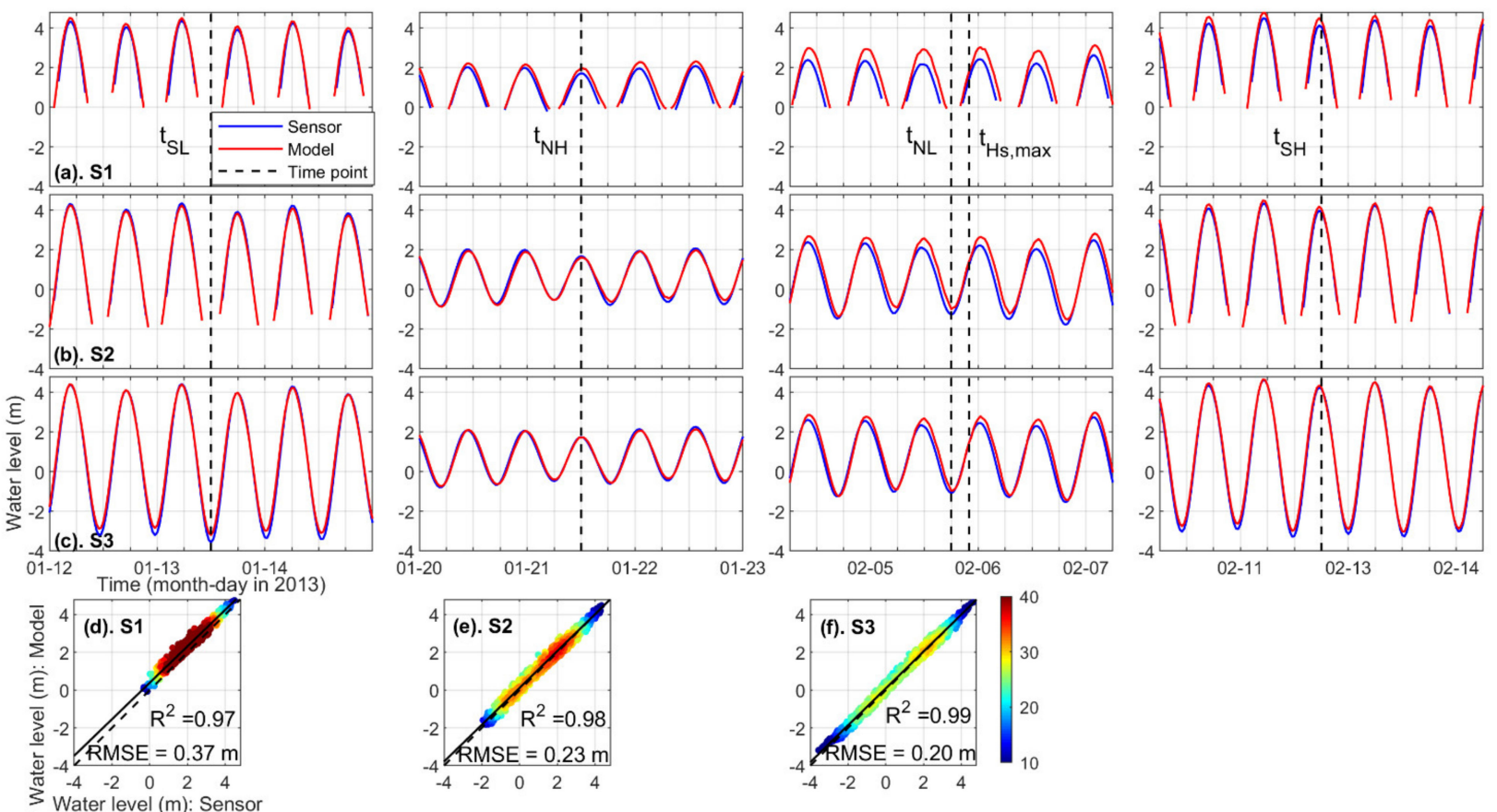

Figure 5. Comparison of the measured (blue) and the simulated (red) water levels at the pressure sensor locations: (a) S1, (b) S2, and (c) S3 (see Figure 4). For clarity, the comparisons were made around four time points (columns of a,b,c), $\mathrm{t}_{\mathrm{SL}}$ : 2013-01-13 12:00 (spring-low water), $\mathrm{t}_{\mathrm{NH}}$ : 2013-01-21 12:00 (neap-high), $\mathrm{t}_{\mathrm{NL}}$ : 2013-02-05 18:00 (neap-low), $\mathrm{t}_{\mathrm{SH}}$ : 2013-02-11: 18:00 (spring-high), where the time of occurrence of the peak storm wave height is also indicated $t_{\mathrm{Hs}, \max }: 2013-02-0522: 00$ (just after $t_{\mathrm{NL}}$ ). Scatter plots of measured and simulated water levels during the analysis period for (d) S1, (e) S2, and (f) S3, showing the calculated linear regression (solid line), perfect agreement (dashed line), and density of data points by percentage (color).

The wave height and directional distribution were analyzed qualitatively at the selected time points for the G2 (a) and G3 (b) domains (Figure 6). At all of the selected times, waves approached from the northwest. The largest wave heights $(7.5 \mathrm{~m})$ in the G2 domain were observed during the storm peak on 5 February 2013, in the middle of the flood phase of a neap tidal cycle $\left(0.6 \mathrm{~m}\right.$ at $\left.\mathrm{t}_{\mathrm{Hs} \text {,max }}\right)$. However, the largest waves propagating to the beach (G3 domain) occurred at spring-high tide $\left(t_{\mathrm{SH}}\right)$, when the offshore water level and wave height were about $3.5 \mathrm{~m}$ and $4.5 \mathrm{~m}$, respectively. Given the high water level, the waves propagated farther shoreward before being dissipated, impacting higher elevations on the beach. On the contrary, during spring-low tide ( $\left.\mathrm{t}_{\mathrm{SL}}\right)$, a large part of the study area became dry, limiting wave propagation to deeper water depths $(>3.5 \mathrm{~m})$. The tide level and its impact on wave propagation to the beach thus has an important role in controlling nearshore wave dynamics.

As noted previously, both simulated and measured wave heights at S1, S2, and S3 were modulated by the tide level. At the pressure sensor locations, the simulated wave heights were consistently larger than the measured wave heights (Figure $7 \mathrm{a}-\mathrm{c}$ ). The absolute differences ranged between $0.1-0.9 \mathrm{~m}$ (average $=0.4 \mathrm{~m}$ ) at $\mathrm{S} 1,0.1-1.6 \mathrm{~m}$ (average $=0.6 \mathrm{~m}$ ) at $\mathrm{S} 2$, and $0.8-1.4 \mathrm{~m}$ (average $=0.5 \mathrm{~m}$ ) at $\mathrm{S} 3$, with slightly better agreement during some time periods (e.g., around $t_{\mathrm{NH}}$ ). However, the simulated wave heights showed the same pattern of oscillations as in the data, indicating that the model correctly captured the phase of wave height changes relative to the tide level. The simulated wave heights at $\mathrm{S} 1$ agreed better with the data $(R M S E=0.43 \mathrm{~m})$ than at S2 $(0.66 \mathrm{~m}), \mathrm{S} 3(0.57 \mathrm{~m})$, and W2 $(0.57 \mathrm{~m})$. This could be due to the fact that the vertical position of the $\mathrm{S} 1$ pressure sensor was more stable than the other two pressure sensors. At W2, the WW3 model predicted stronger tidal modulation than the present simulation with Delft3D, particularly during spring tide, thus the agreement between the two models improved during neap tide (Figure 7d). These 
differences may have also been caused by forcing the SWAN model with uniform offshore wave conditions.

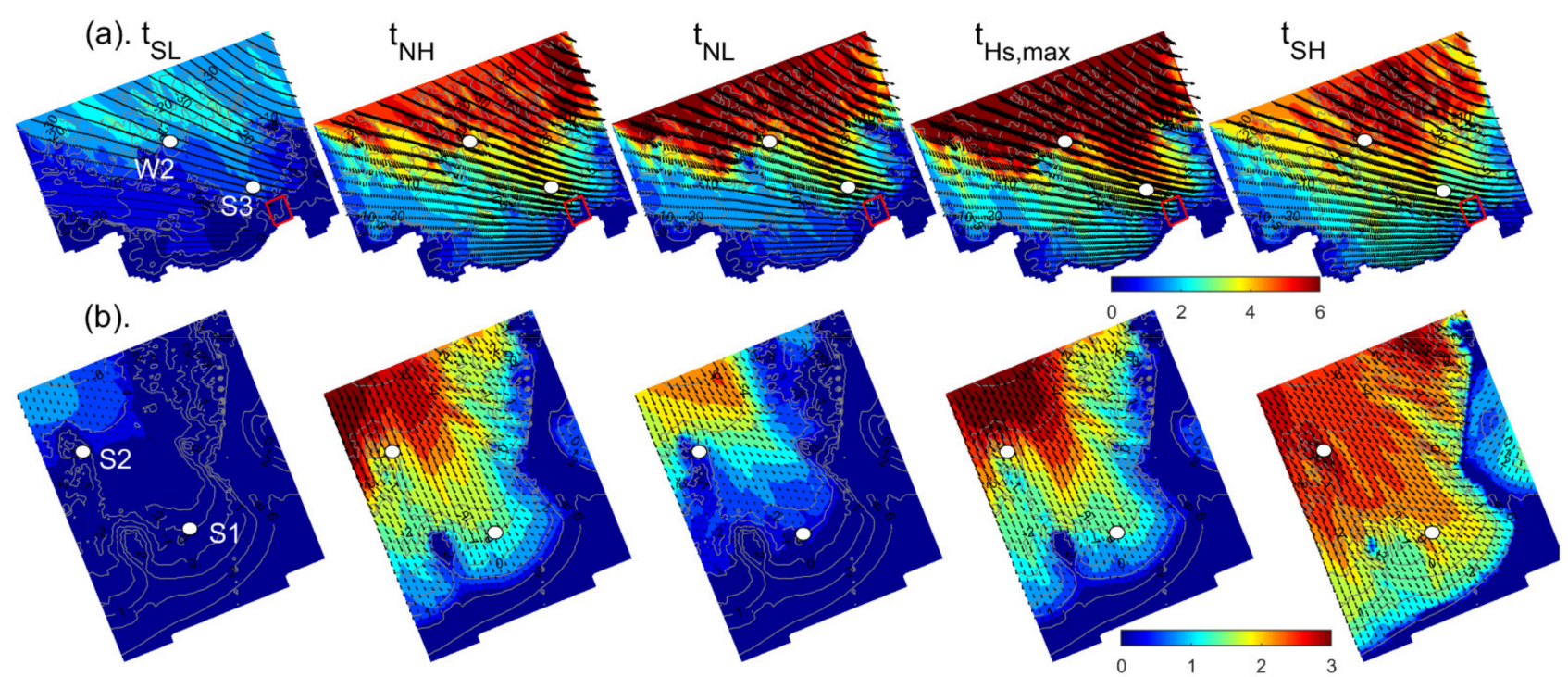

Figure 6. Wave height (color) and direction (vectors) in the G2 (a) and G3 (b) model domains at the selected five dates, $\mathrm{t}_{\mathrm{SL}}$ : spring-low water, $\mathrm{t}_{\mathrm{NH}}$ : neap-high, $\mathrm{t}_{\mathrm{NL}}$ : neap-low, $\mathrm{t}_{\mathrm{Hs} \text {,max }}$ : peak storm wave height, $\mathrm{t}_{\mathrm{SH}}$ : spring-high. $\mathrm{S} 1, \mathrm{~S} 2$, and $\mathrm{S} 3$ indicate the locations of the pressure sensors, and W2 indicates the location of the wave time series obtained from WW3. The red rectangles in (a) show the location of the G3 domain.

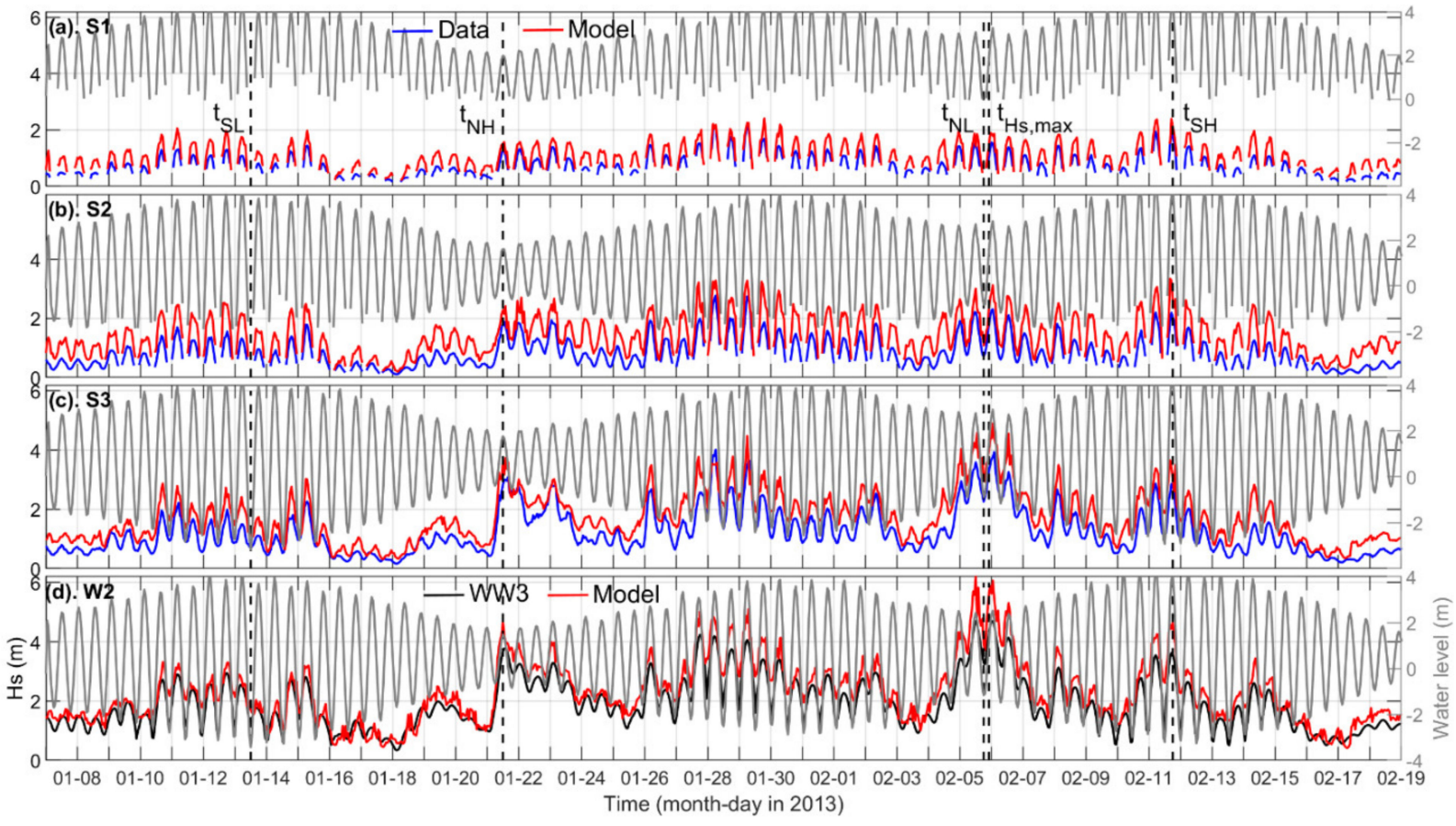

Figure 7. Comparison of the measured (blue) and the simulated (red) wave heights at the pressure sensor locations: (a) S1, (b) S2, and (c) S3 (see Figure 6). (d) Comparison of wave heights at W2 from WW3 (black line) and the present Delft3D model (red line). The gray line indicates the simulated water levels and the vertical dashed lines indicate the selected dates: $\mathrm{t}_{\mathrm{SL}}$ : spring-low, $\mathrm{t}_{\mathrm{NH}}$ : neap-high, $\mathrm{t}_{\mathrm{NL}}$ : neap-low, $\mathrm{t}_{\mathrm{Hs} \text {,max }}$ : peak storm wave height, and $\mathrm{t}_{\mathrm{SH}}$ : spring-high water.

The model validation showed that the measured and simulated water levels agreed well, and that the tide level had a strong impact on nearshore wave heights (as expected on a macrotidal beach). The comparison of the simulated and measured wave height time 
series at the selected locations showed fair agreement (with RMSE ranging from 0.43-0.66). Overall, the reference simulation predicted large wave heights, which could be expected due to a number of reasons that are discussed in Section 5. For the remainder of this study, the simulated results presented in this section are used as the reference case, and all simulations of the future scenarios will be compared to these results to evaluate changes in nearshore hydrodynamics caused by SLR and wave climate changes.

\subsection{Sea Level Rise}

The first simulations of future scenarios considered SLR-only impacts (scenarios 2-4 in Table 2), and the historical wave time series was used as the input wave conditions. The simulated wave height distributions were qualitatively compared to the reference scenario at spring-low $\left(\mathrm{t}_{\mathrm{SL}}\right)$ and spring-high $\left(\mathrm{t}_{\mathrm{SH}}\right)$ tidal levels (Figure 8$)$, representing the extreme tidal excursions and, thus, potential extremes in wave dynamics. The peak storm wave height at $t_{\mathrm{Hs}, \max }$ occurred in the middle of the flood phase of a neap tidal cycle and, thus, even though it corresponded to the largest offshore wave height (7.5 $\mathrm{m}$ at W1), it produced smaller waves in the nearshore region (e.g., at S1-S3: water depth up to $12 \mathrm{~m}$ ) than at $\mathrm{t}_{\mathrm{SH}}(4.5 \mathrm{~m}$ at W1, see Figure 6). The reference scenario showed the smallest wave height distributions at $\mathrm{t}_{\mathrm{SL}}$ (Figure $8 \mathrm{a}$ ) and $\mathrm{t}_{\mathrm{SH}}$ (Figure $8 \mathrm{~b}$ ), and the maximum nearshore wave heights at $t_{\mathrm{SL}}$ increased as the sea level increases (Figure 8a, from left to right). However, at $t_{\mathrm{SH}}$, the maximum nearshore wave heights increased up to SLR $_{\text {avg }}$ and then decreased for $S_{L} R_{\max }$ (Figure 8b), indicating larger wave energy dissipation in the G2 domain in the SLR $R_{\max }$ simulation. Smaller wave heights propagated into the G3 domain (maximum depth $\sim 6 \mathrm{~m}$ ), causing the smallest wave heights at $t_{\mathrm{SH}}$ for the $\mathrm{SLR}_{\max }$ scenario. The wave direction distributions were very similar for all four scenarios, indicating that the different SLR scenarios do not appear to have significant impacts on the observed nearshore wave refraction patterns for the selected incident wave directions, assuming no bathymetric changes. A large difference in wave refraction patterns was observed between two tidal levels ( $t_{\mathrm{SL}}$ and $\mathrm{t}_{\mathrm{SH}}$ ) due to different incident wave conditions.

(a).
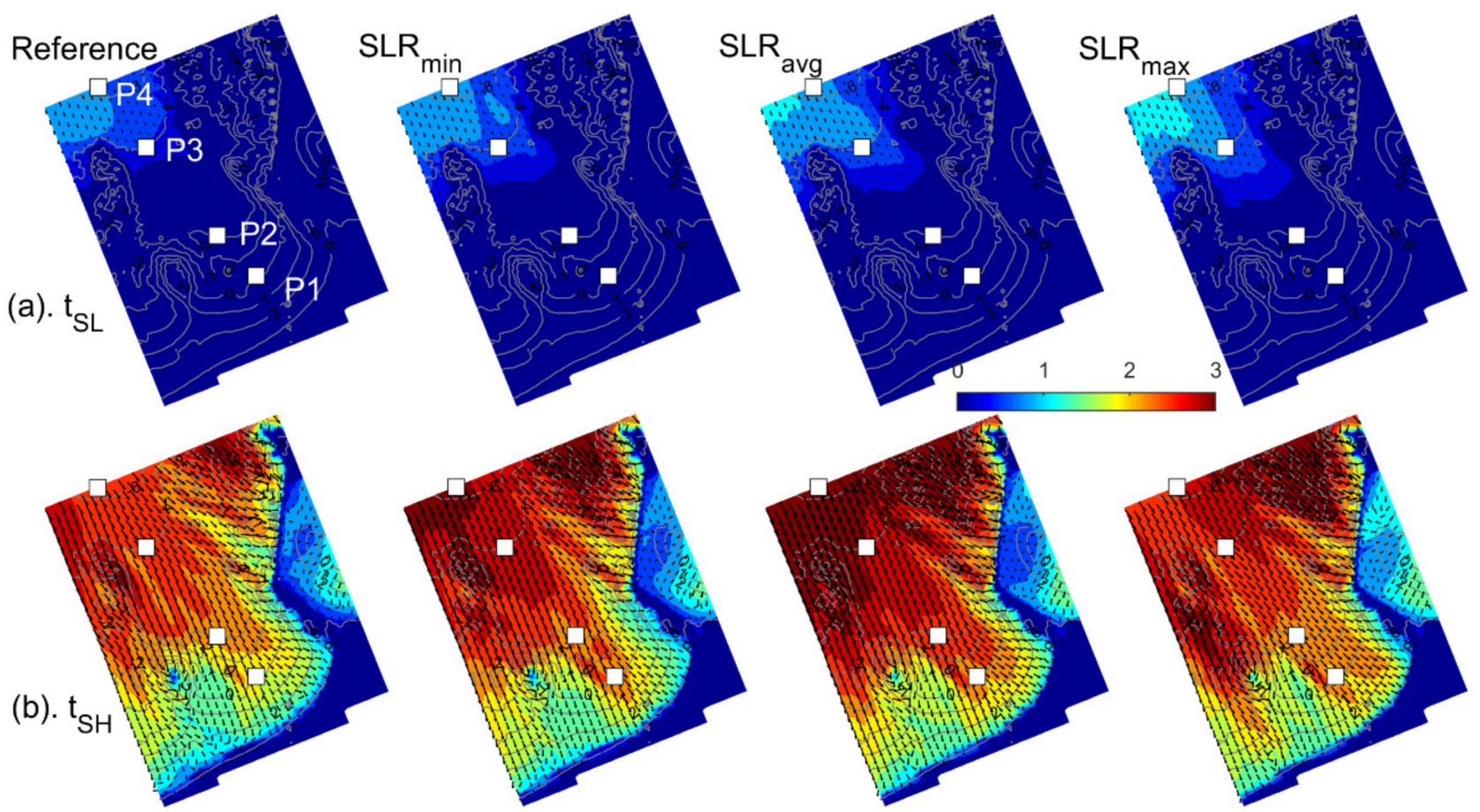

Figure 8. Simulated wave height distributions in the G3 domain for the reference, $\mathrm{SLR}_{\min }, \mathrm{SLR}_{\mathrm{avg}}$, and SLR $\mathrm{R}_{\max } \mathrm{Scenarios}$ for $t_{S L}$ : spring-low water $(\mathbf{a})$ and $t_{S H}$ : spring-high water $(\mathbf{b})$, indicating the analysis locations (white squares) P1 (0 m depth), P2 (2 m), P3 (4 m), and P4 (6.5 m). 
The average wave energy density spectrum $\left(S D_{\text {avg }}\right)$ was calculated for the reference analysis period from 7 January-18 February 2013 and for the future SLR scenarios at four selected locations along a cross-shore profile (P1-P4, see Figure 8). As the water depth increased from P1-P4, SD avg increased, the spectral shape tended to be more skewed, and the spectral peak shifted toward lower frequencies from $0.04 \mathrm{~Hz}$ at P1 to $0.03 \mathrm{~Hz}$ at P4 for all scenarios (Figure 9). At the four selected points, the SLR simulations showed greater $S D_{\text {avg }}$ relative to the reference simulation. In addition, $S D_{a v g}$ also increased with increasing SLR, which is coherent with increases in the spectral energy for increasing water depths. Overall, the differences in SLR scenarios appear to have marginal effects on the average spectral shape.
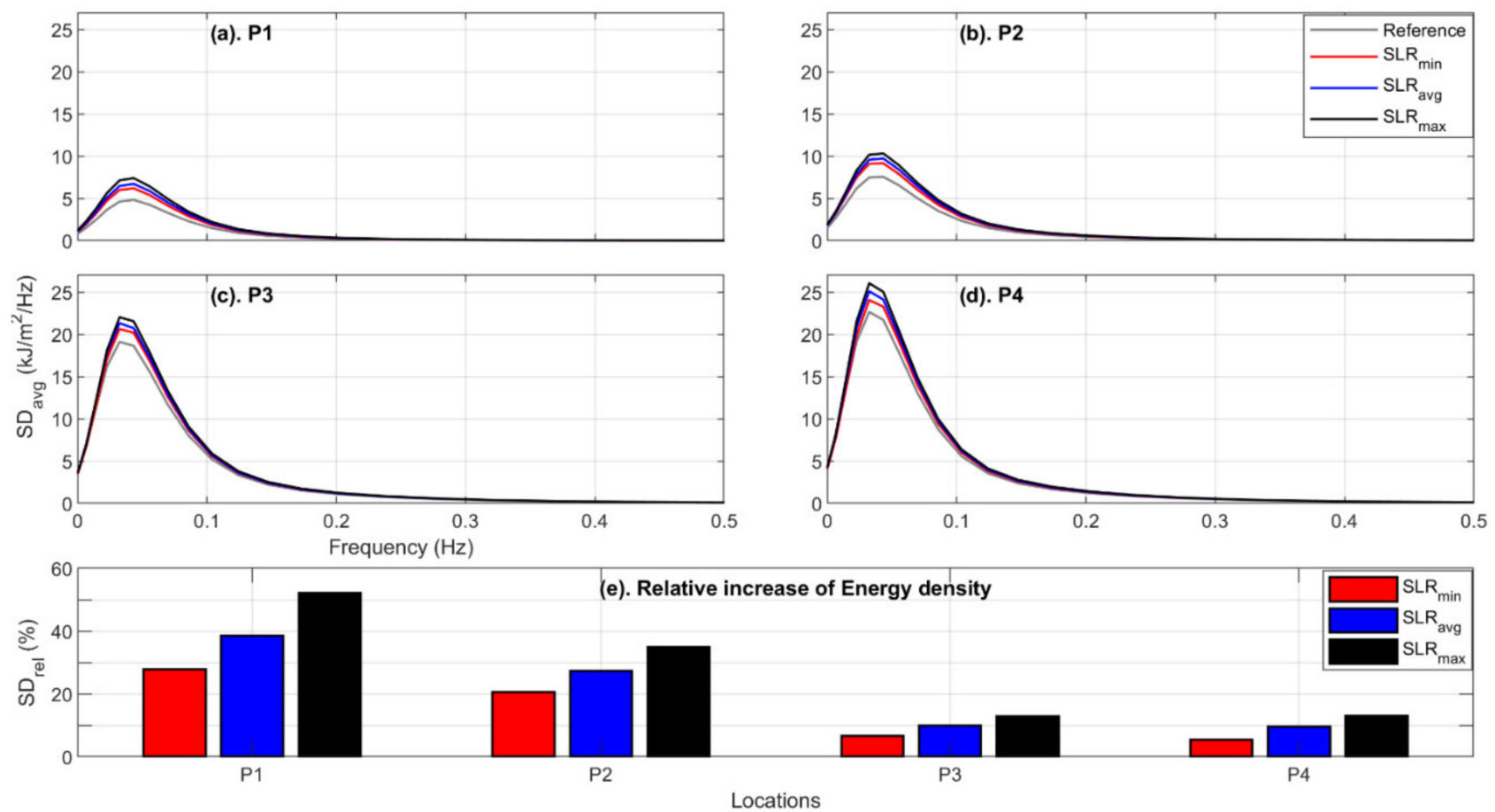

Figure 9. Average wave energy density spectrum ( $S D_{\text {avg: }}$ Equation (2)) during the analysis period from 7 January18 February 2013 for the reference (gray line), $\operatorname{SLR}_{\min }$ (red), SLR avg (blue), and SLR $\max$ (black) scenarios at P1: $0 \mathrm{~m}$ depth (a), P2: 2 m depth (b), P3: $4 \mathrm{~m}$ depth (c), and P4: $6.5 \mathrm{~m}$ depth (d) in the G3 domain (see Figure 8). (e) Relative increases in the wave energy density spectra with respect to the reference scenario $\left(S D_{\text {rel }}\right.$ : Equation (3)).

At each location, the relative change in the average spectral density (Figure 9e) increased with increased sea level (e.g., smallest and largest increases correspond to SLR $R_{\min }$

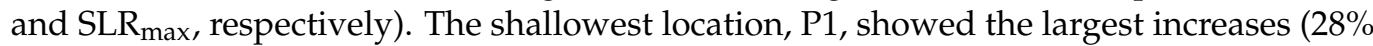
for $S_{L R} R_{\min }, 38 \%$ for $S L R_{a v g}$ and $52 \%$ for $S_{L R}$ max ) and was, thus, most strongly impacted by SLR. The impacts decreased with increasing water depth, showing a significant drop between P1 to P2, and even smaller impacts at P3 and P4, with increases of only 5-15\%. As may be expected, SLR had the strongest effects on wave dynamics in shallow water.

\subsection{Sea Level Rise and Future Wave Climates}

Similar to the previous analysis, the combined effects of SLR and changes in the wave climate on the wave dynamics are shown at spring-low $\left(t_{S L}\right)$ and spring-high $\left(t_{S H}\right)$ tide (Figure 10) for the four combined scenarios (5-8, Table 2).

The simulation results showed increases in wave height for all four scenarios at both tide levels (Figure 10), with noticeable impacts of the effects of SLR. At $t_{\mathrm{SL}}$, the wave heights increased with increased SLR. However, at $t_{\mathrm{SH}}$, the changes due to SLR depended on the wave projection scenario. For A1B (offshore conditions: $H_{S}=4.3 \mathrm{~m}$ and Dir. $=303^{\circ}$ ), the 
largest nearshore wave heights were observed for the $\mathrm{SLR}_{\max }$ simulation. The wave heights in the B1 scenarios were smaller than those of the A1B scenario. For B1 (offshore conditions: $H_{S}=4.7 \mathrm{~m}$ and Dir. $=303^{\circ}$ ), the nearshore wave heights were fairly similar for SLR $\min$ and $\mathrm{SLR}_{\text {max }}$. Therefore, changes in both wave height and direction resulted in different wave propagation processes (shoaling, refraction, and dissipation) as a function of SLR, with complex impacts on the overall wave dynamics.

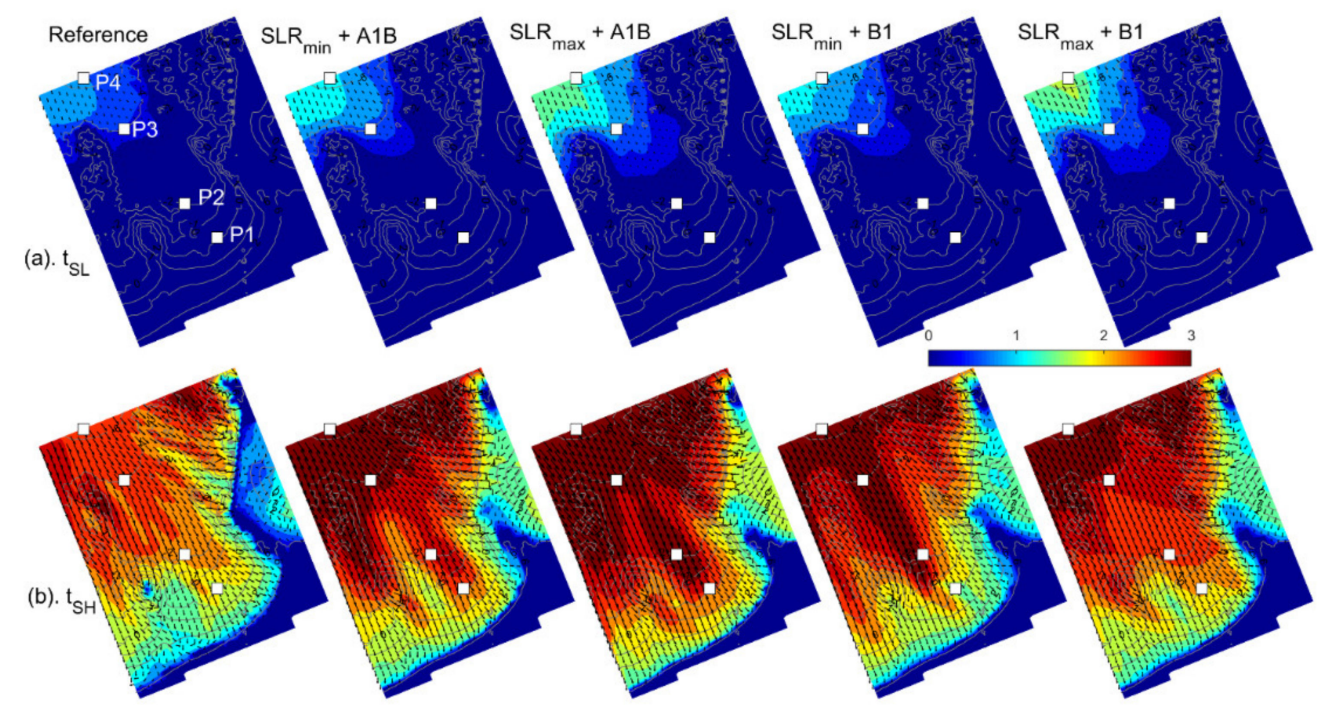

Figure 10. Simulated wave height distributions in the G3 domain for the reference, $S_{L} R_{\min }+\mathrm{A} 1 \mathrm{~B}$, $\mathrm{SLR}_{\max }+\mathrm{A} 1 \mathrm{~B}, \mathrm{SLR}_{\min }+\mathrm{B} 1$, and $\mathrm{SLR}_{\max }+\mathrm{B} 1$ scenarios at $\mathrm{t}_{\mathrm{SL}}$ : spring-low water (a) and $\mathrm{t}_{\mathrm{SH}}$ : springhigh water (b), indicating the analysis locations (white squares) P1 (0 m depth), P2 (2 m), P3 (4 m), and P4 (6.5 m).

The $S D_{a v g}$ of the combined A1B wave climate and SLR scenarios showed increases relative to the reference scenario (Figure 11), and these differences were larger than those observed for the SLR-only scenarios (Section 4.2, Figure 9). The largest increases in wave height occurred in shallow water (P1) and then decreased moving offshore into deeper water (P4). The $S D_{a v g}$ values for both A1B scenarios were significantly larger than that of the reference simulation, but the mean peak frequency remained similar. In contrast, the $S D_{a v g}$ for both B1 scenarios decreased relative to the reference simulation and showed an increase in the average peak frequency (up to $0.09 \mathrm{~Hz}$, relative to $0.03 \mathrm{~Hz}$, Figure $11 \mathrm{a}-\mathrm{d}$ ). Here, the nearshore wave conditions were impacted both by changes in wave propagation and transformation due to changes in the water level (and resultant currents) and by differences in the wave boundary conditions.

In contrast to the SLR scenarios (Section 4.2), $S D_{\text {rel }}$ did not decrease monotonically with increasing water depth (Figure 11e). For example, for the SLR $_{\text {min }}+$ A1B scenario, P1 experienced the largest increase (62\%) and P3 experienced the smallest increase (35\%). The largest overall increases in $S D_{\text {rel }}$ occurred for the $S L R_{\max }+\mathrm{A} 1 \mathrm{~B}$ scenario at all locations (maximum 95\% at P1 and minimum 41\% at P3). In contrast, $S D_{\text {rel }}$ decreased for the $\mathrm{SLR}_{\text {min }}+\mathrm{B} 1$ scenario (maximum $29 \%$ at P3 and minimum 14\% at P2). These results indicate that the larger offshore waves in the B1 wave climate dissipated more than those of the A1B wave climate, for both SLR scenarios. These results indicate that the combined SLR and the future wave climate scenarios caused complex changes in the nearshore wave dynamics that may be more strongly dominated by the wave climate than by SLR. 

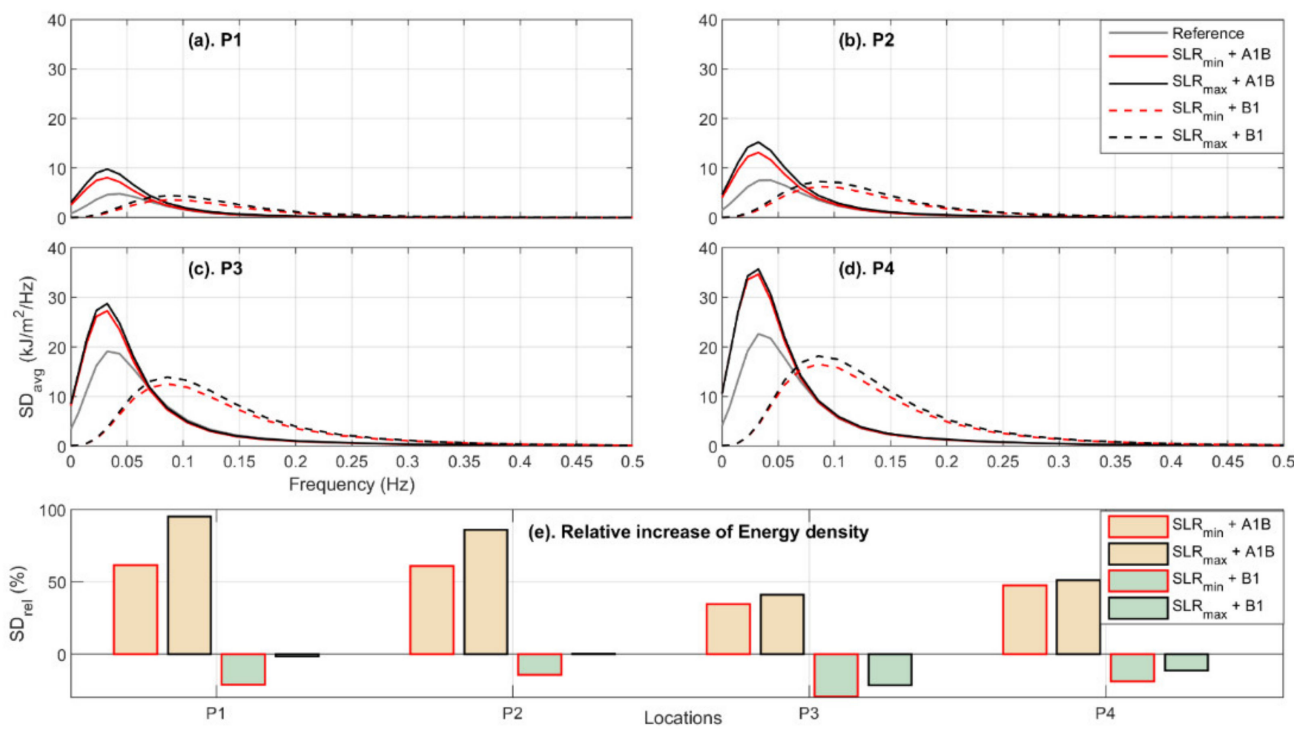

Figure 11. Average wave energy density spectrum $\left(S D_{\text {avg }}\right)$ during the analysis period from 7 January18 February 2013 for the reference (gray line), $\mathrm{SLR}_{\min }+\mathrm{A} 1 \mathrm{~B}$ (red), $\mathrm{SLR}_{\max }+\mathrm{A} 1 \mathrm{~B}$ (black), SLR $\min +\mathrm{B} 1$ (red-dashed), and SLR $\max +$ B1 (black-dashed) at P1: $0 \mathrm{~m}$ depth (a), P2: $2 \mathrm{~m}$ depth (b), P3: $4 \mathrm{~m}$ depth (c), and P4: $6.5 \mathrm{~m}$ depth (d) in the G3 domain (see Figure 10). (e) Relative increase in the wave energy density spectra with respect to the reference scenario $\left(S D_{\text {rel }}\right)$.

To investigate the impacts that the changes in wave and current dynamics may have on sediment transport processes, the average effective bed shear stress $\left(\tau_{b, a v g}\right)$ was evaluated (Figure 12). This term depends on the hydrodynamic forcing (waves and currents) and the local morphology. At P1, the reference scenario had the lowest bed shear stress (Figure 12a), which increased with increasing the sea level rise (SLR-only scenarios). A similar trend was observed at P2. In the reference scenario, P1 and P2 were submerged during only part of the tidal cycle. The length of the submerged periods increased with increasing SLR, resulting in higher $\tau_{b, a v g}$ than the reference scenario. P3 and P4 were permanently submerged, and thus increases in sea level caused decreases in $\tau_{b, a v g}$ relative to the reference. P3 experienced the highest $\tau_{b, a v g}$ in all scenarios, as well as the largest variability during the analysis period (error bars, Figure 12). P3 is located in the nearshore zone, which is surrounded by shallower areas to the east and west (see bathymetry in Figure 4d), causing higher velocities and larger $\tau_{b, a v g}$ than at the other three locations. The variability in changes in $\tau_{b, a v g}$ as a function of SLR and wave climate scenarios makes it difficult to identify the causes of the changes. However, the combined A1B scenarios resulted in large increases in $\tau_{b, a v g}$ at all locations. The large wave heights in the nearshore zone of the A1B scenarios caused higher velocities than in the B1 scenarios. The relative increase in $\tau_{b, a v g}$ showed that P1 was most sensitive to changes in the water level and wave climate, and this effect decreased with increasing water depth (Figure 12b). At P3, both the SLR-only and combined scenarios caused small changes in $\tau_{b, a v g}$ relative to the reference scenario. Therefore, the shallowest water depths at Vougot Beach showed the largest changes in waves in all future scenarios and may be the most vulnerable to wave impacts.

The statistical analyses of changes in wave height are summarized in Table 3. The effects of SLR on wave heights $(H s)$ increased in shallow water, as seen by the increases in the averaged normalized difference $(\bar{\mu})$ and the relative standard deviation $\left(\sigma_{r e l}\right)$. This trend increased with increases in sea level rise. The combined scenarios had stronger impacts on the wave height and, thus, showed lower correlation coefficients $\left(R^{2}\right)$ and higher root mean square difference $(R M S D)$ values than the SLR-only scenarios. Furthermore, the A1B scenarios had larger impacts on the nearshore wave heights than the B1 scenarios, and in both cases, the effect on wave heights increased with increasing SLR. 


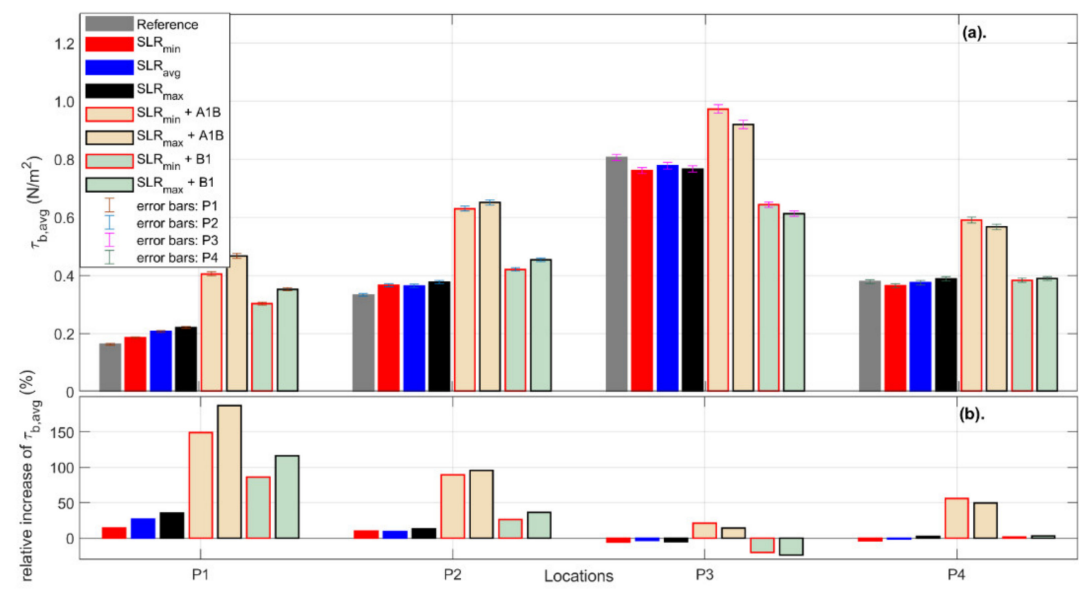

Figure 12. Average effective bed shear stress $\left(\tau_{b, a v g}\right)$ during the analysis period from 7 January18 February 2013 (a) for the reference (gray bar), SLR $\min$ (red), SLR avg (blue), SLR $\max$ (black), $\mathrm{SLR}_{\min }+\mathrm{A} 1 \mathrm{~B}$ (yellow red-enclosed), $\mathrm{SLR}_{\max }+\mathrm{A} 1 \mathrm{~B}$ (yellow black-enclosed), $\mathrm{SLR}_{\text {min }}+\mathrm{B} 1$ (green red-enclosed), and SLR $\max +$ B1 (green black-enclosed) at P1 (0 m depth), P2 (2 m), P3 (4 m), and P4 $(6.5 \mathrm{~m})$ on the $\mathrm{G} 3$ domain (see Figure 10). Standard error (standard deviation/ $\sqrt{ }$ number of time steps) is shown by error bars. Relative increase of $\tau_{b, a v g}(\mathbf{b})$ is shown with the corresponding color bars.

Table 3. Statistical parameters comparing the difference between the reference and the future scenarios in wave height (Hs) at P1 (0 m depth), P2 (2 m), P3 (4 m), and P4 (6.5 m) (see location in Figure 10). $R^{2}$ : correlation coefficient, $R M S D$ : root mean square difference, $\bar{\mu}$ : averaged normalised difference, $\sigma_{\text {rel }}$ : relative standard deviation.

\begin{tabular}{|c|c|c|c|c|c|c|}
\hline & \multirow[t]{2}{*}{ Scenario } & \multirow[t]{2}{*}{ Parameter } & \multicolumn{4}{|c|}{$\begin{array}{l}\text { Wave Height (Hs) } \\
\text { Location }\end{array}$} \\
\hline & & & P1 & $\mathbf{P} 2$ & P3 & P4 \\
\hline \multirow{12}{*}{ 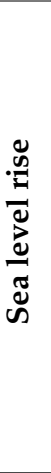 } & \multirow{4}{*}{$S_{L R} \min$} & $R^{2}(-)$ & 0.93 & 0.94 & 0.92 & 0.94 \\
\hline & & $R M S D(\mathrm{~m})$ & 0.19 & 0.17 & 0.20 & 0.19 \\
\hline & & $\bar{\mu}(-)$ & 0.31 & 0.21 & 0.06 & 0.04 \\
\hline & & $\sigma_{r e l}(\mathrm{~m})$ & 0.67 & 0.43 & 0.13 & 0.09 \\
\hline & \multirow{4}{*}{ SLR $_{\text {avg }}$} & $R^{2}(-)$ & 0.88 & 0.92 & 0.90 & 0.92 \\
\hline & & $R M S D(\mathrm{~m})$ & 0.25 & 0.22 & 0.24 & 0.22 \\
\hline & & $\bar{\mu}(-)$ & 0.43 & 0.30 & 0.08 & 0.05 \\
\hline & & $\sigma_{r e l}(\mathrm{~m})$ & 0.90 & 0.59 & 0.15 & 0.11 \\
\hline & \multirow{4}{*}{$\mathrm{SLR}_{\max }$} & $R^{2}(-)$ & 0.85 & 0.91 & 0.88 & 0.93 \\
\hline & & $R M S D(\mathrm{~m})$ & 0.31 & 0.26 & 0.27 & 0.23 \\
\hline & & $\bar{\mu}(-)$ & 0.53 & 0.38 & 0.10 & 0.07 \\
\hline & & $\sigma_{r e l}(\mathrm{~m})$ & 1.10 & 0.73 & 0.17 & 0.11 \\
\hline \multirow{16}{*}{ 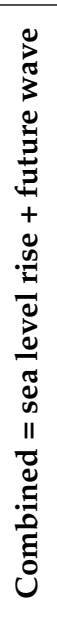 } & \multirow{4}{*}{$\mathrm{SLR}_{\min }+\mathrm{A} \mathbf{1 B}$} & $R^{2}(-)$ & 0.90 & 0.89 & 0.87 & 0.87 \\
\hline & & $R M S D(\mathrm{~m})$ & 0.26 & 0.29 & 0.31 & 0.39 \\
\hline & & $\bar{\mu}(-)$ & 0.40 & 0.42 & 0.18 & 0.21 \\
\hline & & $\sigma_{r e l}(\mathrm{~m})$ & 0.59 & 0.64 & 0.21 & 0.20 \\
\hline & \multirow{4}{*}{$\mathrm{SLR}_{\max }+\mathrm{A} \mathbf{1 B}$} & $R^{2}(-)$ & 0.84 & 0.86 & 0.84 & 0.84 \\
\hline & & $R M S D(\mathrm{~m})$ & 0.38 & 0.40 & 0.36 & 0.43 \\
\hline & & $\bar{\mu}(-)$ & 0.62 & 0.63 & 0.22 & 0.24 \\
\hline & & $\sigma_{r e l}(\mathrm{~m})$ & 0.97 & 1.00 & 0.26 & 0.23 \\
\hline & \multirow{4}{*}{$\mathrm{SLR}_{\min }+\mathrm{B} 1$} & $R^{2}(-)$ & 0.87 & 0.85 & 0.80 & 0.76 \\
\hline & & RMSD (m) & 0.19 & 0.27 & 0.33 & 0.43 \\
\hline & & $\bar{\mu}(-)$ & 0.24 & 0.34 & 0.13 & 0.21 \\
\hline & & $\sigma_{r e l}(\mathrm{~m})$ & 0.46 & 0.58 & 0.29 & 0.32 \\
\hline & \multirow{4}{*}{$\mathrm{SLR}_{\max }+\mathrm{B} 1$} & $R^{2}(-)$ & 0.81 & 0.82 & 0.77 & 0.75 \\
\hline & & $R M S D(\mathrm{~m})$ & 0.31 & 0.36 & 0.38 & 0.50 \\
\hline & & $\bar{\mu}(-)$ & 0.46 & 0.54 & 0.20 & 0.27 \\
\hline & & $\sigma_{r e l}(\mathrm{~m})$ & 0.81 & 0.89 & 0.31 & 0.33 \\
\hline
\end{tabular}




\section{Discussion}

The objective of this study was to evaluate the impacts of climate change on the coastal wave dynamics at Vougot Beach, including not only SLR, but also combined scenarios of SLR and wave climate changes to respond to the increasing need to investigate the interactions between these two factors [60]. Simulations were carried out for a 6-week period during the 2012-2013 winter (validation and reference period) and for the same 6-week period projected into the future using the selected SLR and wave climate scenarios (Table 2) to quantify the projected changes in the significant wave height $H s$, the average wave energy density spectra $S D_{a v g}$, and the effective bed shear stress $\tau_{b}$. The simulation results showed the importance of both SLR and wave climate changes, and, in particular, interactions between the complex nearshore bathymetry and the macrotidal regime of the beach.

\subsection{Macrotidal Beach Dynamics}

The impacts of SLR and wave climate changes on the nearshore wave dynamics were most significant at high tide. This is particularly important for beach morphodynamics since changes in the hydrodynamic conditions at high tide have stronger impacts on beach and dune morphological changes [61-63]. Recent modelling studies of the predicted impacts of past and future storms on the morphology of a macrotidal beach also emphasized the importance of the water level on the impact of storm events $[6,35]$. However, Bennett et al. [35], stated that there is high variability between different sites, and while the SLR-only simulations in the current study were in agreement with their conclusion, the combined SLR and wave scenarios emphasized the importance of interactions between water levels and waves. Thus, although high spatial and temporal resolution modelling efforts are computationally expensive, they may provide evidence of the complexities of beach hydrodynamics, which have important impacts on beach and dune morphological changes.

\subsection{Uncertainties in the Modelling Approach}

The results presented here should not be interpreted as deterministic predictions of future beach hydrodynamics, but rather as a preliminary estimation of potential changes in nearshore hydrodynamics and their dependency on SLR and wave climate changes. This modelling approach depends on the accuracy of the model calibration and the forcing data, including, in particular, the predictions of future SLR and wave climate scenarios.

\subsubsection{Model Calibration Uncertainties}

The validation of the model simulations showed good agreement between the simulated and measured water levels (Figure 5), with high correlations $\left(R^{2}>0.97\right)$ and low errors $(R M S E<0.37 \mathrm{~m}$ ) between the two time series at the locations of the three pressure sensors. However, errors between the simulated and measured Hs were larger, with RMSE ranging from $0.43-0.66 \mathrm{~m}$ (average difference in $H s \sim 0.5 \mathrm{~m}$ ) at the three pressure sensors, and comparisons between Delft3D and WW3 estimated wave heights at the point W2 showed a RMSD of $0.57 \mathrm{~m}$. These differences may have been caused by errors in the numerical model or in the wave heights estimated from the pressure sensor measurements.

Errors in the numerical model may have been caused by a number of different factors including the model inputs, calibration, boundary conditions, bathymetric grid, and simulated physical processes. The input wave conditions were obtained from WW3 simulations at a grid point located in $44 \mathrm{~m}$ water depth, and errors between the in situ and WW3-simulated wave heights were not able to be estimated at this location. At a wave buoy located nearby in $60 \mathrm{~m}$ depth (Pierres Noires, buoy 62069), the estimated RMSE and bias were 0.13 and $0.05 \mathrm{~m}$, respectively [34].

In the model, the wave conditions were assumed to be constant along the offshore boundary, with a constant $40 \mathrm{~m}$ water depth, which likely caused the model to overestimate the wave height at the eastern end, which is shallower than the western end. The submarine scarp between $10 \mathrm{~m}$ and $40-60 \mathrm{~m}$ depth that delimits the outer edge of the 
large platform with reefs and islets was not well reproduced in the bathymetry data. The nearshore bathymetry was represented well with a high-resolution grid, but the offshore bathymetry may not have been represented accurately given the high spatial variability in the offshore zone at this site. The bathymetry remained constant in time, and the impacts of morphological changes on wave propagation were not considered. Finally, the SWAN model likely overestimates wave heights [28], and does not simulate accurately diffraction processes [64], which were therefore not included in the simulations. At Vougot Beach, diffraction may be important, and refraction and depth-induced processes may have also not been represented accurately enough.

The model was calibrated using bed friction and wave breaking parameters. Water level and currents in Delft3D are sensitive to the bed friction [65]. A Chézy coefficient of $60 \mathrm{~m}^{1 / 2} / \mathrm{s}$ was selected following a sensitivity analysis of the water levels. Simulated wave heights in SWAN depend on the parameterization of the wave energy dissipation [28]. A friction coefficient of $0.06 \mathrm{~m}^{2} / \mathrm{s}^{3}$ and a wave breaking parameter of 0.65 were selected for the SWAN model by qualitatively comparing the simulated and measured wave heights. However, an extensive calibration and validation were not undertaken, and the simulated and observed wave heights showed fair agreement (Section 4.1). These values remained constant in all simulations, and only the relative changes between the reference and future scenarios were analyzed.

In addition to errors related to the numerical modelling, some of the differences between the simulated and measured wave heights may have been caused by errors in the wave height time series calculated from the pressure sensor measurements. The pressure sensors were located in $0.7 \mathrm{~m}$ (S1), $2.5 \mathrm{~m}$ (S2), and $12 \mathrm{~m}$ (S3) water depths, and S3 was the only sensor that remained permanently submerged. Sensors S1 and S2 were, thus, located in the surf zone, where waves may be highly nonlinear and even breaking. Linear reconstruction of wave heights from pressure sensors underestimates $\mathrm{Hs}$ in shallow water [66], leading to up to a $30 \%$ underestimation of individual wave heights near the breaking point $[67,68]$. Due to pressure attenuation at S3, only wave periods larger than around $3 \mathrm{~s}$ could be measured. This served as a high-frequency cutoff for the wave spectrum and may have shifted the computed significant wave height. Thus, the reconstruction method used to calculate the wave height at the pressure sensor locations, in addition to intrinsic instrument measurement errors, may have also contributed to the observed differences between the simulated and measured wave heights.

\subsubsection{Projected SLR and Future Wave Time Series}

It has been assumed that the primary driver of climate change impacts to the wave field comes from the meteorological forcing, and changes in the local bathymetry have not been considered. This study thus relied on accurate projections of sea level and local wave climate changes. The SLR predictions were global averages extracted from the 5th IPCC report [12], spanning the range of changes expected by 2100. Although global values were used in this study, regional-scale predictions fall within the global range (Section 3.1.1), and therefore the SLR predictions were assumed to be representative of expected future changes.

Future estimates of the wave climate are more difficult to obtain, in particular at local scales. At global scales, large differences exist in different wave forecasting models, as highlighted by the COWCLIP (Coordinated Ocean Wave Climate Project) project [29] and by the IPCC 5th Assessment Report [12], which assigned low confidence to wave projections. Thus, more recently, a series of ten new global wind-wave projection studies were completed using atmospheric forcing from the CMIP5 GCM simulations, highlighting that the uncertainties in wave predictions are dominated by climate model-driven uncertainties [69] leading to uncertainties of up to $\sim 50 \%$ in single-method modelling studies. One must be careful in interpreting single, deterministic simulations of wave climate changes, thinking of these predictions as estimates of the possible changes in the local wave field. 
The availability of ensemble averages of predicted wave fields at the global scale is useful for global-scale studies, but additional methods must be used to transform these wave conditions to local wave conditions. In this study, the statistics of the hindcast and forecast waves time series (using the dynamical downscaling approach of Laugel [45]) were used to estimate transfer functions to project the historical reference time series to the equivalent time series in 2100 (following Banno and Kuriyama [26]). A second set of linear transfer functions was used to transform these offshore wave conditions (W0) to the nearshore zone (W1) to use as input wave conditions in the Delft3D model. The estimates of future wave conditions could be improved by using ensemble averages of hindcast and future wave projections instead of the results from a single wave model. However, ensemble averages of future wave simulations are not yet readily available at worldwide scales, in particular in the nearshore zone. If ensemble averages of offshore waves exist, they must be propagated to the coastline, which requires setting up computationally intensive intermediate- to local-scale models or developing site-specific downscaling approaches.

\subsection{Extension of the Modelling Approach}

The availability of data for setting up, forcing, and calibrating numerical models (e.g., bathymetric and hydrodynamic measurements) is crucial to assess model performance and to obtain accurate results. The present modelling approach could be improved using extended offshore bathymetry data and measured offshore waves. This study was particularly focused on a six-week period during the 2012-2013 winter, but the study could be extended to investigate storm events with different hydrodynamic conditions (e.g., the energetic storms of the 2008 or 2013/2014 winter [70,71], events with different combinations of water levels and wave heights [6]) to generalize the conclusions presented here. Future work includes extending this work to evaluate the impacts on the beach and dune morphodynamics, including interactions between the hydrodynamics and changes in the nearshore bathymetry. This could facilitate improving the model predictions by considering temporal variations in the bathymetry, which were not considered here, as well as evaluating potential coastal erosion risks, dune breaching, and hinterland flooding. Lastly, the approach developed here can be applied to a wide variety of sites with sufficient bathymetric, wave, and water level observations to calibrate and validate the modelling approach before simulating future events using projections of future waves and water levels.

\section{Conclusions}

Wave dynamics at Vougot Beach were investigated using Delft3D to simulate a 6-week period in 2013 and seven projected scenarios in 2100, including three SLR-only scenarios and four combined SLR and wave climate change scenarios. The SLR-only scenarios showed that increased water levels allowed larger waves to propagate farther onshore, and the differences in wave heights were most significant in shallow water. The simulations of the combined SLR and wave scenarios showed the importance of evaluating the two effects simultaneously because the scenario showing the largest increases in nearshore wave heights did not correspond to the scenario with the largest offshore waves. Given the complex nearshore bathymetry and macrotidal regime of the beach, it is necessary to simulate the local-scale hydrodynamics with a high-resolution model to represent accurately the interactions between waves and water levels.

Future studies are required using improved wave projections, in particular in the nearshore environment, to gain a more comprehensive understanding of the potential changes in currents and waves, as well as their impacts. The approach presented here, as well as its extension to evaluate climate change impacts on nearshore sediment transport and morphological evolution, can thus be applied to other coastal systems to study localscale changes in hydrodynamics and, ultimately, morphodynamics, providing useful information for beach management and policy makers. 
Author Contributions: Conceptualization, P.D. and M.L.Y.; methodology, P.D. and M.L.Y.; software, P.D.; validation, P.D.; formal analysis, P.D. and M.L.Y.; investigation, P.D. and M.L.Y.; resources, P.D., M.L.Y. and S.S.; data curation, P.D., M.L.Y., S.S., F.F. and K.K.; writing-original draft preparation, P.D. and M.L.Y.; writing—review and editing, P.D., M.L.Y., S.S., F.F. and K.K.; visualization, P.D. and M.L.Y.; supervision, P.D., M.L.Y. and S.S.; project administration, P.D., M.L.Y. and S.S.; funding acquisition, P.D., S.S. and F.F. All authors have read and agreed to the published version of the manuscript.

Funding: This research was funded by German Research Foundation (DFG), grant number DI 2139/2-1 and the APC was funded by the same grant. The hydrodynamic survey was funded by the "Institut National des Sciences de l'Univers" (INSU-CNRS) in the framework of the French "Service National d'Observation" (SNO-DYNALIT). The equipment for hydrodynamic survey was funded by the Labex-Mer (ANR-10-LABX-19), and by an ISblue project, Interdisciplinary graduate school for the blue planet (ANR-17-EURE-0015).

Acknowledgments: This study is part of the MoDECS (Modification of Dune Erosion by adjacent Coastal Systems) project funded by German Research Foundation (DFG) under the grant number DI 2139/2-1. Field surveys at Vougot Beach were supported by the "Institut National des Sciences de l'Univers" (INSU-CNRS) in the framework of the French "Service National d'Observation" (SNODYNALIT), the Labex-Mer (ANR-10-LABX-19), and by an ISblue project, Interdisciplinary graduate school for the blue planet (ANR-17-EURE-0015). It was co-funded by a grant from the French government under the program "Investissements d'Avenir", the municipality of Guissény, Europe for Economic and Regional Development, the Regional Council of Brittany, and Finistère department as part of the CPER projects.

Conflicts of Interest: The authors declare no conflict of interest.

\section{References}

1. Chowdhury, P.; Behera, M.R. Effect of long-term wave climate variability on longshore sediment transport along regional coastline. Prog. Oceanogr. 2017, 156, 145-153. [CrossRef]

2. Harley, M.D.; Ciavola, P. Managing local coastal inundation risk using real-time forecasts and artificial dune placements. Coast. Eng. 2013, 77, 77-90. [CrossRef]

3. Hunt, S.; Bryan, K.R.; Mullarney, J.C. The effect of wind waves on spring-neap variations in sediment transport in two meso-tidal estuarine basins with contrasting fetch. Geomorphology 2017, 280, 76-88. [CrossRef]

4. $\quad$ Rosenberger, K.J.; Storlazzi, C.D.; Cheriton, O.M.; Pomeroy, A.W.M.; Hansen, J.F.; Lowe, R.J.; Buckley, M.L. Spectral Wave-Driven Bedload Transport Across a Coral Reef Flat/Lagoon Complex. Front. Mar. Sci. 2020, 7, 875. [CrossRef]

5. Yang, G.; Wang, X.H.; Zhong, Y.; Cheng, Z.; Andutta, F.P. Wave effects on sediment dynamics in a macro-tidal estuary: Darwin Harbour, Australia during monsoon season. Estuar. Coast. Shelf Sci. 2020, 244, 106931. [CrossRef]

6. Dissanayake, P.; Brown, J.; Sibbertsen, P.; Winter, C. Using a two-step framework for the investigation of storm impacted beach/dune erosion. Coast. Eng. 2021, 168, 103939. [CrossRef]

7. Dissanayake, P.; Brown, J.; Wisse, P.; Karunarathna, H. Effect of storm clustering on beach/dune evolution. Mar. Geol. 2015, 370, 63-75. [CrossRef]

8. Huang, S.Y.; Yen, J.Y.; Wu, B.L.; Shih, N.W. Field observations of sediment transport across the rocky coast of east Taiwan: Impacts of extreme waves on the coastal morphology by Typhoon Soudelor. Mar. Geol. 2020, 421, 106088. [CrossRef]

9. Suanez, S.; Romain, C.; Floc'h, F.; Blaise, E.; Ardhuin, F.; Filipot, J.F.; Cariolet, J.M.; Delacourt, C. Observations and Predictions of Wave Runup, Extreme Water Levels, and Medium-Term Dune Erosion during storm conditions. J. Mar. Sci. Eng. 2015, 3, 674-698. [CrossRef]

10. Suanez, S.; Cariolet, J.M.; Cancouët, R.; Ardhuin, F.; Delacourt, C. Dune recovery after storm erosion on a high-energy beach: Vougot beach, Brittany (France). Geomorphology 2012, 139, 16-33. [CrossRef]

11. Van Ormondt, M.; Nelson, T.R.; Hapke, C.J.; Roelvink, D. Morphodynamic modelling of the wilderness breach, Fire Island, New York. Part I: Model set-up and validation. Coast. Eng. 2020, 157, 103621. [CrossRef]

12. Church, J.A.; Clark, P.U.; Cazenave, A.; Gregory, J.M.; Jevrejeva, S.; Levermann, A.; Merrifield, M.A.; Milne, G.A.; Nerem, R.S.; Nunn, P.D.; et al. Sea Level Change. In Climate Change 2013: The Physical Science Basis. Contribution of Working Group I to the Fifth Assessment Report of the Intergovernmental Panel on Climate Change; Stocker, T.F., Qin, D., Plattner, G.-K., Tignor, M., Allen, S.K., Boschung, J., Nauels, A., Xia, Y., Bex, V., Midgley, P.M., Eds.; Cambridge University Press: Cambridge, UK; New York, NY, USA, 2013.

13. Mentaschi, L.; Vousdoukas, M.I.; Voukouvalas, E.; Dosio, A.; Feyen, L. Global changes of extreme coaszal wave energy fluxes triggered by intensified teleconnection patterns. Geophys. Res. Lett. 2017, 44, 2416-2426. [CrossRef]

14. Neumann, B.; Vafeidis, A.T.; Zimmermann, J.; Nicholls, R.J. Future coastal population growth and exposure to sea-level rise and coastal flooding-A global assessment. PLOS ONE 2015, 10, e0131375. [CrossRef]

15. Ranasinghe, R. On the need for a new generation of coastal change models for the 21st century. Sci. Rep. 2020, 10, 1-6. [CrossRef] 
16. Vousdoukas, I.; Ranasinghe, R.; Mentaschi, L.; Plomaritis, T.A.; Athanasiou, P.; Luijendijk, A.; Feyen, L. Sand coastlines under threat of erosion. Nat. Clim. Chang. 2020, 10, 260-263. [CrossRef]

17. McGranahan, G.; Balk, D.; Anderson, B. The rising tide: Assessing the risks of climate change and human settlements in low elevation coastal zones. Environ. Urban 2007, 19, 17-37. [CrossRef]

18. Vendel, A.L.; Lopes, S.G.; Santos, C.; Spach, H.L. Fish assemblages in a tidal flat. Braz. Arch. Biol. Technol. 2003, 46, $233-242$. [CrossRef]

19. De Jong, F.; Bakker, J.F.; van Berkel, C.J.M.; Dankers, N.M.J.A.; Dahl, K.; Gätje, C.; Marencic, H.; Potel, P. Wadden Sea Quality Status Report, 1999; Wadden Sea Ecosystem No. 9; Common Wadden Sea Secretariat, Trilateral Monitoring and Assessment Group, Quality Status Report Group: Wilhelmshaven, Germany, 1999.

20. Bruun, P.M. Sea level rise as a cause of shore erosion. J. Waterw. Harb. Div. 1962, 88, 117-130. [CrossRef]

21. Hinkel, J.; Lincke, D.; Vafeidis, A.T.; Perrette, M.; Nicholls, R.J.; Tol, R.S.J.; Marzeion, B.; Fettweis, X.; Ionescu, C.; Levermann, A. Coastal food damage and adaptation costs under 21st century sea-level rise. Proc. Natl. Acad. Sci. USA 2014, 111, 3292-3297. [CrossRef] [PubMed]

22. Jiménez, J.A.; Sanchez-Arcille, A. Physical impacts of climatic change on deltaic coastal systems (II): Driving terms. Clim. Chang. 1997, 35, 95-118. [CrossRef]

23. Cooper, J.A.G.; Masselink, G.; Coco, G.; Short, A.D.; Castelle, B.; Rogers, K.; Anthony, E.; Green, A.N.; Kelley, J.T.; Pilkey, O.H.; et al. Sandy beaches can survive sea-level rise. Nat. Clim. Chang. 2020, 10, 993-995. [CrossRef]

24. O'Grady, J.G.; Hemer, M.A.; McInees, K.L.; Trenham, C.E.; Stephenson, A.G. Projected incremental changes to extreme winddriven wave heights for the twenty-first century. Sci. Rep. 2021, 11, 8826. [CrossRef]

25. Vousdoukas, M.I.; Mentaschi, L.; Voukouvalas, E. Global probabilistic projections of extreme sea levels show intensification of coastal flood hazards. Nat. Commun. 2018, 9, 2360. [CrossRef]

26. Banno, M.; Kuriyama, Y. Prediction of future shoreline change with sea-level rise and wave climate change at Hasaki, Japan. In Proceedings of the 33rd International Conference of Coastal Engineering, Seoul, South Korea, 30 October 2014.

27. Hemer, M.A.; Fan, Y.; Mori, N.; Semedo, A.; Wang, X. Projected changes in wave climate from a multi-model ensemble. Nat. Clim. Chang. 2013, 3, 471-476. [CrossRef]

28. Boyd, S.C.; Weaver, R.J. Replacing a third-generation wave model with a fetch based parametric solver in coastal estuaries. Estuar. Coast. Shelf Sci. 2021, 251, 107192. [CrossRef]

29. Divinsky, B.O.; Kosyan, R.D. Influence of the climatic variations in the wind waves parameters on the alongshore sediment transport. Oceanologia 2020, 62, 190-199. [CrossRef]

30. Medellín, G.; Mayor, M.; Appendini, C.M.; Cerezo-Mota, R.; Jiménez, J.A. The Role of Beach Morphology and Mid-Century Climate Change Effects on Wave Runup and Storm Impact on the Northern Yucatan Coast. Mar. Sci. Eng. 2021, 9, 518. [CrossRef]

31. Dodet, G.; Bertin, X.; Taborda, R. Wave climate variability in the North-East Atlantic Ocean over the last six decades. Ocean Model. 2010, 31, 120-131. [CrossRef]

32. Booij, N.; Ris, R.C.; Holthuijsen, L.H. A third-generation wave model for coastal regions, Part I, Model description and validation. J. Geophys. Res. 1999, 104, 7649-7666. [CrossRef]

33. Lesser, G.; Roelvink, J.A.; Van Kester, J.A.T.M.; Stelling, G.S. Development and validation of a three-dimensional morphological model. Coast. Eng. 2004, 51, 883-915. [CrossRef]

34. Boudière, E.; Maisonidieu, C.; Ardhuin, F.; Accensi, M.; Pineau-Guillou, L.; Lepesqueur, J. A suitable metocean hindcast database for the design of marine energy converters. Int. J. Mar. Energy 2013, 3, E40-E52. [CrossRef]

35. Bennett, W.G.; Karunarathna, H.; Reeve, D.; Mori, N. Computational modelling of morphodynamic response of a macro-tidal beach to future climate variabilities. Mar. Geol. 2019, 415, 105960. [CrossRef]

36. Battistini, R. Le littoral septentrional du Léon: Principaux problèmes morphologiques. Bull. L'association Géographes Français 1953, 30, 58-71. [CrossRef]

37. Battistini, R. Description du relief et des formations quaternaires du littoral breton entre Brignogan et Saint-Pol-de-Léon (Finistère). Bulletin d'Information du Comité Central d'Océanographie et d'Etude des Côtes 1955, 7, 468-491.

38. Battistini, R.; Martin, S. La "Plate-forme à écueils" du Nord-Ouest de la Bretagne. Norois 1956, 10, 147-161. [CrossRef]

39. Guilcher, A.; Hallégouët, B. Coastal dunes in Brittany and their management. J. Coast. Res. 1991, 7, 517-533.

40. Suanez, S.; Cariolet, J.M.; Fichaut, B. Monitoring of Recent Morphological Changes of the Dune of Vougot Beach (Brittany, France) Using Differential GPS. Shore Beach 2010, 78, 37-47.

41. Bishop, C.T.; Donelan, M.A. Measuring waves with pressure transducers. Coast. Eng. 1987, 11, 309-328. [CrossRef]

42. Homma, M.; Horikawa, K.; Komori, S. Response characteristics of underwater wave gauge. Coast. Eng. Jpn. 1966, 9, 45-54. [CrossRef]

43. Pierson, W.J.; Marks, W. The power spectrum analysis of ocean-wave records. Eos Trans. Am. Geophys. Union 1952, 33, 834-844. [CrossRef]

44. IAHR Working Group on Wave Generation and Analysis. List of sea-state parameters. J. Waterw. Port Coast. Ocean. Eng. 1989, 115, 793-808. [CrossRef]

45. Laugel, A. Climatologie des états de mer en Atlantique nord-est: Analyse du Climat Actuel et des Evolutions Futures sous Scénarios de Changement Climatique, par Descente D'échelle Dynamique et Statistique. Ph.D. Thesis, Université Paris Est, Laboratoire d'Hydraulique Saint-Venant, Chatou, France, 2013. 
46. Benoit, M.; Marcos, M.; Becq, F. Development of a third generation shallow-water wave model with unstructured spatial meshing. In Proceedings of the 25th International Conference on Coastal Engineering, Orlando, FL, USA, 2-6 September 1996; pp. 465-478.

47. Salas-Mélia, D.; Chauvin, F.; Déqué, M.; Douville, H.; Guérémy, J.F.; Marquet, P.; Planton, S.; Royer, J.F.; Tyteca, S. Description and Validation of CNRM-CM3 Global Coupled Climate Modele; Technical Report Note de centre GMGEC 103; CNRM: Toulouse, France, 2005.

48. Intergovernmental Panel on Climate Change (IPCC). Climate Change 2007: The Physical Science Basis Summary for Policymakers; IPPC: Geneva, Switzwerland, 2007; 18p.

49. Dissanayake, P.; Winter, C. Modelling the coastline orientation on storm erosion at the Sylt island, North Sea. In Proceedings of the Virtual Conference of Coastal Engineering, 6-9 October 2020. 36v, paper 20.

50. Stelling, G.S. On the construction of computational methods for shallow water flow problem. In Rijkswaterstaat Communications; Governing Printing Office: Hague, The Netherlands, 1984; Volume 35.

51. Stelling, G.S.; Lendertse, J.J. Approximation of Convective Processes by Cyclic ACI methods. In Proceedings of the 2nd ASCE Conference on Estuarine and Coastal Modelling, Tampa, FL, USA, 13-15 November 1991.

52. Roelvink, J.A.; Walstra, D.J. Keeping it simple by using complex models. Adv. Hydrosci. Eng. 2004, V1, 1-11.

53. Donelan, M.A.; Hamilton, H.; Hui, W.H. Directional spectra of wind-generated waves. Philos. Trans. R. Soc. Lond. A 1985, 315, 509-562.

54. Hasselmann, K.; Barnett, T.P.; Bouws, F.; Carlson, H.; Cartwright, D.E.; Enke, K.; Ewing, J.A.; Gienapp, H.; Hasselmann, D.E.; Krusemann, P.; et al. Measurements of Windwave Growth and Swell Decay during the Joint North Sea Wave Project (JONSWAP); Deutches Hydrographisches Institut, A8: Hamburg, Germany, 1973; pp. 1-95.

55. Nair, M.A.; Kumar, V.S. Wave spectral shapes in the coastal waters based on measured data off Karwar on the western coast of India. Ocean. Sci. 2017, 13, 365-378. [CrossRef]

56. Soulsby, R. Dynamics of Marine Sands, a Manual for Practical Applications; Thomas Telford: Teleford, UK, 1997.

57. Fredsøe, J. Turbulent boundary layer in wave-current interaction. J. Hydraul. Eng. 1984, 110, 1103-1120. [CrossRef]

58. Amoudry, L.O.; Souza, A.J. Deterministic coastal morphological and sediment transport modelling: A review and discussion. Rev. Geophys. 2011, 49, RG2002. [CrossRef]

59. Krause, P.; Boyle, D.P.; Bäse, F. Comparison of different efficiency criteria for hydrological model assessment. Adv. Geosci. 2005, 5, 89-97. [CrossRef]

60. Brooks, N.; Nicholls, R.; Hall, J. Sea Level Rise: Coastal Impacts and Responses. In Expertise for WBGU on Oceans and Global Change; WBGU: Berlin, Germany, 2006; p. 49.

61. Masselink, G. Simulating the Effects of Tides on Beach Morphodynamics. J. Coast. Res. 1993, SI 15, $180-197$.

62. Sabatier, F.; Anthony, E.J.; Héquette, A.; Suanez, S.; Musereau, J.; Ruz, M.H.; Regnauld, H. Morphodynamics of beach/dune systems: Examples from the coast of France. Géomorphologie Relief Process. Environ. 2009, 15, 3-22. [CrossRef]

63. Wright, L.D.; Nielsen, P.; Short, A.D.; Green, M.O. Morphodynamics of a macrotidal beach. Mar. Geol. 1982, 50, 97-127. [CrossRef]

64. Kim, G.H.; Jho, M.H.; Yoon, S.B. Improving the performance of SWAN modelling to simulate diffraction of waves behind structures. J. Coast. Res. 2017, SI 79, 349-353. [CrossRef]

65. Hsu, Y.L.; Dykes, J.D.; Allard, R.A. Evaluation of Delft3D Performance in Nearshore Flows; Naval Research Laboratory, Ocean Dynamics and Prediction Branch, Stennis Space Center: Hancock, MS, USA, 2006.

66. Tsai, C.H.; Huang, M.C.; Young, F.J.; Lin, Y.C.; Li, H.W. On the recovery of surface wave by pressure transfer function. Ocean. Eng. 2005, 32, 1247-1259. [CrossRef]

67. Bonneton, P.; Lannes, D. Recovering water wave elevation from pressure measurements. J. Fluid Mech. 2017, 833, 399-429. [CrossRef]

68. Martins, K.; Blenkinsopp, C.E.; Almar, R.; Zang, Z. On the influence of swash-based reflection on surf zone hydrodynamics: A wave-by-wave approach. Coast. Eng. 2017, 122, 27-43. [CrossRef]

69. Morim, J.; Hemer, M.A.; Wang, X.L.; Cartwright, N.; Trenham, C.; Semedo, A. Robustness and uncertainties in global multivariate wind-wave climate projections. Nat. Clim. Chang. 2019, 9, 711-718. [CrossRef]

70. Masselink, G.; Castelle, B.; Scott, T.; Dodet, G.; Suanez, S.; Jackson, D.; Floc’h, F. Extreme wave activity during 2013/2014 winter and morphological impacts along the Atlantic coast of Europe. Geophys. Res. Lett. 2016, 43, 2135-2143. [CrossRef]

71. Ruju, A.; Filiplo, J.F.; Bentamy, A.; Leckler, F. Spectral wave modelling of the extreme 2013/2014 winter storms in the North-East Atlantic. Ocean. Eng. 2020, 216, 108012. [CrossRef] 